D.O.I.:10.3895/S1808-04482012000100009

\title{
MODELO MULTICRITÉRIO PARA AVALIAÇÃO E SELEÇÃO DE PROJETOS DE PESQUISA E DESENVOLVIMENTO EM UMA EMPRESA DISTRIBUIDORA DE ENERGIA
}

\section{MULTICRITERIA MODEL FOR EVALUATION AND SELECTION OF PROJECTS OF RESEARCH AND DEVELOPMENT IN AN ENERGY COMPANY}

\author{
Leonardo Ensslin ${ }^{1}$; Maurício Andreis ${ }^{2}$; Thalita Assad Medaglia ${ }^{3}$; Haline De Carli ${ }^{4}$; Sandra Rolim \\ Ensslin 5 \\ ${ }^{1}$ Universidade Federal de Santa Catarina - UFSC - Florianópolis - Brasil \\ leonardoensslin@gmail.com \\ ${ }^{2}$ Universidade Federal de Santa Catarina - UFSC - Florianópolis - Brasil \\ mauricioandreis@gmail.com \\ ${ }^{3}$ Universidade Federal de Santa Catarina - UFSC - Florianópolis - Brasil \\ thalitamedaglia@gmail.com \\ ${ }^{4}$ Universidade Federal de Santa Catarina - UFSC - Florianópolis - Brasil \\ halinedecarli@gmail.com \\ ${ }^{5}$ Universidade Federal de Santa Catarina - UFSC - Florianópolis - Brasil \\ sensslin@gmail.com
}

\begin{abstract}
Resumo
O mundo observa um crescimento de aplicações de recursos em pesquisas para desenvolvimento de novos produtos elou novas tecnologias. Para atender essas necessidades, as empresas usualmente depositam na área de Pesquisa e Desenvolvimento $(P \& D)$ a responsabilidade pelo processo de geração, seleção e implementação dos projetos. O objetivo deste trabalho, de natureza descritiva e exploratória, é apresentar um processo metodológico para construir um modelo que apóie a construção do conhecimento dos atores de uma empresa específica no que se refere à identificação de oportunidades para construir elou aperfeiçoar projetos de Pesquisa \& Desenvolvimento (P\&D). O processo metodológico proposto é ilustrado para uma organização voltada para a inovação. Foram construídos seus objetivos estratégicos para a área de $P \& D$ e explicitados os indicadores de desempenho-ID que os operacionalizam. Este conhecimento permitiu evidenciar que os objetivos estratégicos; "Econômico" e "Componentes" são responsáveis por quase 50\% do que a empresa busca com os projetos de P\&D. A metodologia utilizada disponibiliza aos gestores conhecimento materializado em um modelo que captou a percepção dos mesmos para explicitar os aspectos por eles julgados como necessários e suficientes para representar o que buscam na área de $P \& D$. $O$ processo utilizado construiu escalas para mensurar os aspectos considerados como necessários e suficientes para avaliar o grau de desenvolvimento de novos produtos elou novas tecnologias e as integrou permitindo ser utilizado como processo para gerar aperfeiçoamento dos projetos $e$ mensurar suas contribuições.
\end{abstract}

Palavras-chave: pesquisa e desenvolvimento; avaliação; metodologia multicritério de apoio à decisão - construtivista (MCDA-C). 


\section{Introdução}

$\mathrm{Na}$ busca por clientes em mercados de competitividade extrema, as empresas têm encontrado nos aperfeiçoamentos e inovações um nicho sustentável. Para atender a essas necessidades, as empresas depositam na área de Pesquisa e Desenvolvimento (P\&D) a responsabilidade pelo processo de geração, seleção e implementação de seus projetos.

O processo de desenvolvimento e seleção de projetos de $\mathrm{P} \& \mathrm{D}$ é reconhecido como um problema multicritério de elevada complexidade onde os objetivos são conflitantes, competem pelos mesmos escassos recursos, não estão claramente identificados e, por serem tanto qualitativos como quantitativos, requerem conhecimentos especiais para sua mensuração (ENSSLIN et al., 2001). Esta situação remete a que o problema de avaliação e seleção de projetos de P\&D é uma situação mal estruturada que requer o uso de instrumentos de pesquisa que reconheçam a necessidade de construir o conhecimento específico demandado em um nível que explicite os requisitos (objetivos) e suas escalas de mensuração.

Inúmeras são as metodologias multicritérios para seleção, dentre um conjunto de alternativas conhecidas, aquela que apresenta melhor desempenho. A questão proposta neste contexto, no entanto, encontra-se em um estágio anterior e mais abrangente a esta situação. No presente caso os decisores tem um conhecimento incompleto e não organizado sobre quais os requisitos a serem tidos em conta e como medir seu desempenho segundo a percepção do cliente. O problema consiste em primeiramente utilizar instrumentos de pesquisa que ajudem aos atores a explicitar e mensurar os aspectos que segundo estes agregam valor ao produto. Em um segundo momento estabelecer as performances de referência e o desempenho atual, e em um terceiro momento gerar as alternativas para melhorar o desempenho atual e selecionar as melhores.

Neste contexto, emerge a pergunta de pesquisa que guiará o trabalho: quais são os aspectos a serem considerados em um processo de seleção de projetos de $\mathrm{P} \& \mathrm{D}$ para uma empresa distribuidora de energia de tal forma a tornar tal empresa mais competitiva em seu mercado?

Com o intuito de responder à pergunta de pesquisa proposta, o objetivo deste trabalho é construir um modelo de avaliação que auxilie o decisor a compreender as potencialidades e oportunidades de aperfeiçoamento para enfrentar os desafios do negócio no processo de desenvolvimento e seleção de projetos de P\&D. Tendo em vista a necessidade de expansão do entendimento do contexto pelos atores será utilizada como instrumento de pesquisa a metodologia MCDA-C por sua capacidade de construir conhecimento em contextos complexos (ENSSLIN et al., 2010).

O uso da metodologia MCDA-C permitirá ao decisor (i) identificar, (ii) organizar, (iii) mensurar, (iv) integrar e, (v) gerenciar, segundo sua percepção, os aspectos críticos para o sucesso da área de P\&D da empresa em estudo, com vistas a assegurar um diferencial competitivo nesta 
área. Adicionalmente, o resultado do processo de operacionalização da metodologia MCDA-C permitirá a identificação dos aspectos em que o projeto não atende as expectativas da equipe de $\mathrm{P} \& \mathrm{D}$, ou seja, atender à etapa de gerenciamento. A expansão do conhecimento permitirá ao decisor, de uma forma transparente e cientificamente fundamentada, avaliar e selecionar projetos de P\&D existentes, assim como gerar novos que melhor atendam os interesses da organização.

Este trabalho está dividido da seguinte forma: após esta seção introdutória, encontra-se a metodologia de pesquisa, a qual exibe o enquadramento metodológico de pesquisa, além do procedimento de pesquisa para a revisão da literatura. Em seguida o referencial teórico expõe o conceito de avaliação de desempenho adotado pelos autores, a análise das ferramentas utilizadas e os estudos de caso e tendências verificadas. O referencial teórico é seguido pela metodologia da pesquisa, a qual apresenta a Metodologia Muticritério de Apoio à Decisão Construtivista, dividida em três partes: fase de estruturação, avaliação e recomendação. Os resultados são também divididos nas mesmas três partes. Por último, encontram-se as considerações finais, espaço que expõe as conclusões da pesquisa.

\section{Metodologia de pesquisa}

\subsection{Enquadramento metodológico de pesquisa}

A pesquisa pode ser caracterizada como sendo de natureza descritiva e exploratória. Descritiva, por descrever as tendências em estudos nacionais e internacionais sobre a avaliação e seleção de projetos de pesquisa e desenvolvimento (GIL, 2010). A análise dos estudos nacionais e internacionais dos artigos foi realizada a partir da afiliação teórica de avaliação de desempenho adotada nesta pesquisa, possibilitando identificar oportunidades de melhoria nos procedimentos encontrados (ENSSLIN et al., 2010). E exploratória, pois buscou maiores informações sobre os aspectos importantes a serem considerados no modelo de avaliação construído (RICHARDSON, 2008). A busca por maior conhecimento sobre o tema ocorrerá por meio da interação entre o facilitador e o decisor (diretor da área de P\&D da empresa), onde esse irá explicitar suas preocupações sobre o processo de construção de um modelo para avaliar e selecionar projetos de Pesquisa e Desenvolvimento (P\&D) na empresa distribuidora de energia. Em outras palavras, o estudo foi desenvolvido para gerar conhecimento sobre critérios relevantes ao diretor da área de P\&D da empresa de distribuição de energia e também para identificar tendências em importantes publicações do meio científico.

Com relação aos procedimentos técnicos, pode-se classificar o presente estudo como uma pesquisa bibliográfica (GIL, 2010) e um estudo de caso (YIN, 2005). Bibliográfica por utilizar as tendências encontradas na literatura e identificar oportunidades de melhoria a partir da afiliação teórica adotada neste estudo sobre avaliação de desempenho. E estudo de caso, pois esta pesquisa 
tem como objetivo identificar os critérios a serem considerados na avaliação e seleção de projetos de Pesquisa e Desenvolvimento (P\&D) de uma empresa distribuidora de energia, bem como identificar como os mesmos serão mensurados e seus desempenhos gerenciados, a partir das necessidades do departamento de P\&D.

O estudo de caso faz uso de abordagem metodológica quali-quantitativa (RICHARDSON, 2008). A fase de Estruturação é eminentemente qualitativa, enquanto que a fase de Avaliação é qualitativa na análise da independência dos critérios e quantitativa na transformação dos descritores em função de valor (software M-MACBETH), na construção das taxas de compensação (software M-MACBETH), na análise de sensibilidade (software HIVIEW) e no processo de avaliação global do desempenho (por meio da fórmula de agregação aditiva). A fase de recomendações é qualitativa quanto ao processo de gerar ações e quantitativa quanto à mensuração da contribuição de cada uma (por meio da fórmula de agregação aditiva).

A fonte de coleta dos dados é de natureza primária e secundária (RICHARDSON, 2008). Primária com relação à construção do modelo, pelo fato de os dados terem sido coletados diretamente junto ao diretor da área de $\mathrm{P} \& \mathrm{D}$ da empresa por meio de entrevistas semi-estruturadas realizadas individualmente. No que diz respeito à pesquisa e análise bibliográfica, a fonte de coleta de dados pode ser caracterizada como de natureza secundária, pois se utilizou de pesquisa documental nas bases de dados da Capes para identificar e analisar os aspectos importantes nesse tema no âmbito mundial (Procedimentos de Pesquisa para Revisão da Literatura).

Para a construção do modelo, a ferramenta utilizada foi a metodologia Multicritério em Apoio à Decisão Construtivista (MCDA-C). Optou-se por utilizar tal metodologia por sua capacidade de: (i) melhorar o entendimento do contexto segundo a percepção do decisor; (ii) identificar e organizar os objetivos considerados importantes para os decisores no contexto; (iii) construir escalas qualitativas (ordinais) para mensurar o alcance destes objetivos e transformar as escalas para quantitativas (cardinais); (iv) integrar os objetivos por meio das taxas de compensação, possibilitando a construção de um modelo de avaliação global; (v) permitir a compreensão das conseqüências das alternativas nos objetivos, possibilitando a análise do contexto para criar aperfeiçoamentos (ENSSLIN; MONTIBELLER; NORONHA, 2001; ENSSLIN, 2002; ENSSLIN et al., 2010; BORTOLUZZI; ENSSLIN; ENSSLIN, 2011).

Entrevistas semi-estruturadas foram utilizadas para ajudar o decisor a explicitar suas percepções do contexto, organizá-las, construir escalas inicialmente ordinais e posteriormente cardinais, testar a independência entre critérios, integrar os critérios, traçar o perfil do status quo e de alternativas de aperfeiçoamento. A evolução do entendimento do contexto resulta no modelo geral de avaliação que permite ao decisor visualizar as consequências de suas decisões. 


\subsection{Procedimentos de pesquisa para revisão da literatura}

O processo adotado para revisar a literatura existente sobre Avaliação e seleção de projetos de P\&D constitui-se de três principais etapas: Identificação de palavras-chave; Escolha das bases de dados e Pesquisa e seleção das referências pesquisadas. A identificação de palavras-chave realizouse por meio de um processo de Brainstorming com os pesquisadores e orientadores do trabalho. Além disso, utilizou-se de análise crítica do tema de pesquisa "Seleção e Avaliação de Projetos de Pesquisa e Desenvolvimento", objetivando-se explicitar as expressões que poderiam ser utilizadas na literatura para representar o problema do tema de pesquisa. As palavras-chave identificadas foram: "Seleção de projetos, avaliação de desempenho, pesquisa e desenvolvimento, avaliação, processo de decisão".

Iniciou-se então a seleção das bases de dados acessando o site das coleções de bases de dados no Portal de Periódicos da Capes, site que contém uma lista de bases de dados mundiais e uma breve descrição sobre o tipo de conteúdo que estas indexam. Para filtrar as bases de dados optou-se por selecionar as que contivessem em seu nome ou descrição uma das palavras "Engenharia e/ou ciências exatas e/ou administração e/ou multidisciplinar e/ou ciências sociais", com o intuito de obter um conjunto de base de dados que contivesse publicações tão abrangentes quanto possíveis além de associadas ao tema de pesquisa. Assim obtiveram-se as 37 bases de dados conforme Tabela 1.

Tabela 1 - Lista das bases de dados encontradas

\begin{tabular}{|c|c|c|c|c|c|}
\hline Número & Base de Dados & $\begin{array}{c}\text { Palavra } \\
\text { encontrada no } \\
\text { título e/ou } \\
\text { descrição } \\
\end{array}$ & Número & Base de Dados & $\begin{array}{c}\text { Palavra } \\
\text { encontrada no } \\
\text { título e/ou } \\
\text { descrição } \\
\end{array}$ \\
\hline 1 & $\begin{array}{c}\text { American Chemical Society } \\
- \text { ACS }\end{array}$ & Engenharia & 19 & INFORMS & $\begin{array}{l}\text { Administração, } \\
\text { Ciências } \\
\text { Sociais }\end{array}$ \\
\hline 2 & $\begin{array}{l}\text { Applied Science and } \\
\text { Technology Full Text }\end{array}$ & $\begin{array}{l}\text { Ciências } \\
\text { Exatas }\end{array}$ & 20 & $\begin{array}{c}\text { INSPEC (Institution of } \\
\text { Electrical Engineers - IEE) }\end{array}$ & Engenharia \\
\hline 3 & Blackwell & $\begin{array}{l}\text { Ciências } \\
\text { Exatas, } \\
\text { Ciências } \\
\text { Sociais }\end{array}$ & 21 & JSTOR & $\begin{array}{l}\text { Ciências } \\
\text { Sociais }\end{array}$ \\
\hline 4 & Business Full Text & Administração & 22 & $\begin{array}{c}\text { MathSci (American } \\
\text { Mathematical Society) }\end{array}$ & Engenharia \\
\hline 5 & Cambridge University Press & $\begin{array}{l}\text { Ciências } \\
\text { Exatas, } \\
\text { Ciências } \\
\text { Sociais }\end{array}$ & 23 & Nature & Multidisciplinar \\
\hline 6 & $\begin{array}{c}\text { Citas Latinoamericanas en } \\
\text { Ciencias Sociales y } \\
\text { Humanidades : CLASE }\end{array}$ & $\begin{array}{l}\text { Ciências } \\
\text { Sociais }\end{array}$ & 24 & $\begin{array}{c}\text { OECD (Organization for } \\
\text { Economic Co-operation and } \\
\text { Development) }\end{array}$ & Multidisciplinar \\
\hline 7 & $\begin{array}{l}\text { COMPENDEX Ei } \\
\text { Engineering Índex }\end{array}$ & Engenharia & 25 & Oxford University Press & $\begin{array}{l}\text { Ciências } \\
\text { Exatas, } \\
\text { Ciências } \\
\text { Sociais }\end{array}$ \\
\hline 8 & CSA Cambridge Scientific & Engenharia & 26 & Royal Society of Chemistry & Engenharia \\
\hline
\end{tabular}




\begin{tabular}{|c|c|c|c|c|c|}
\hline & Abstracts & & & & \\
\hline 9 & Duke University Press & $\begin{array}{l}\text { Ciências } \\
\text { Sociais }\end{array}$ & 27 & Sage & $\begin{array}{l}\text { Ciências } \\
\text { Sociais }\end{array}$ \\
\hline 10 & $\begin{array}{c}\text { EconLit (American } \\
\text { Economic Association) }\end{array}$ & Administração & 28 & $\begin{array}{c}\text { SciELO - Scientific } \\
\text { Electronic Library Online }\end{array}$ & $\begin{array}{c}\text { Engenharia, } \\
\text { Ciências } \\
\text { Sociais }\end{array}$ \\
\hline 11 & Emerald & $\begin{array}{l}\text { Administração, } \\
\text { Engenharia }\end{array}$ & 29 & Science Direct & $\begin{array}{c}\text { Engenharia, } \\
\text { Ciências } \\
\text { Sociais } \\
\end{array}$ \\
\hline 12 & $\begin{array}{l}\text { FSTA (Food Science and } \\
\text { Technology Abstracts) }\end{array}$ & Engenharia & 30 & $\begin{array}{c}\text { SciFinder Scholar (CAS } \\
\text { Chemical Abstracts Service) }\end{array}$ & Engenharia \\
\hline 13 & Galé & $\begin{array}{c}\text { Ciências } \\
\text { Sociais }\end{array}$ & 31 & Scopus & $\begin{array}{c}\text { Ciências } \\
\text { Sociais }\end{array}$ \\
\hline 14 & General Science Full Text & $\begin{array}{l}\text { Ciências } \\
\text { Exatas }\end{array}$ & 32 & Social Sciences Full Text & Administração \\
\hline 15 & $\begin{array}{c}\text { GeoRef } \\
\text { GeoRef Preview Database }\end{array}$ & Engenharia & 33 & SocIndex with Full Text & $\begin{array}{l}\text { Ciências } \\
\text { Sociais }\end{array}$ \\
\hline 16 & $\begin{array}{c}\text { Handbook of Latin } \\
\text { American Studies : HLAS }\end{array}$ & $\begin{array}{l}\text { Ciências } \\
\text { Sociais }\end{array}$ & 34 & Springer Verlag & $\begin{array}{c}\text { Engenharia, } \\
\text { Ciências } \\
\text { Sociais }\end{array}$ \\
\hline 17 & IEEE/IET & Engenharia & 35 & Web of Science & Multidisciplinar \\
\hline 18 & $\begin{array}{c}\text { Índice de Revistas } \\
\text { Latinoamericanas en } \\
\text { Ciências : PERIÓDICA }\end{array}$ & $\begin{array}{l}\text { Ciências } \\
\text { Exatas }\end{array}$ & 36 & Wilson & $\begin{array}{c}\text { Engenharia, } \\
\text { Ciências } \\
\text { Sociais } \\
\end{array}$ \\
\hline & & & 37 & World Scientific & Engenharia \\
\hline
\end{tabular}

Fonte: Autoria própria (2008)

Como critério de redução das bases de dados selecionadas retirou-se todas as que continham a palavra "chemestry", "chemical" ou "food" no título (Sendo estas as bases de número 1, 12, 26 e 30), por se tratar de assuntos específicos e desalinhados. Para reduzir as bases de dados a um número factível de ser trabalhado, optou-se por pesquisar em todas as bases remanescentes com apenas uma combinação de palavras-chave, considerada a mais importante para os pesquisadores, sendo esta "Research and Development" "Evaluation". Esta pesquisa foi realizada somente no título, resumo e palavras-chave dos artigos, considerando apenas aqueles publicados após o ano 2000. Os resultados estão explicitados no Gráfico 1. 
Gráfico 1 - Análise de composição dos resultados da pesquisa para selecionar bases de dados

\section{Resultados para ""Research and Development" "Evaluation""}

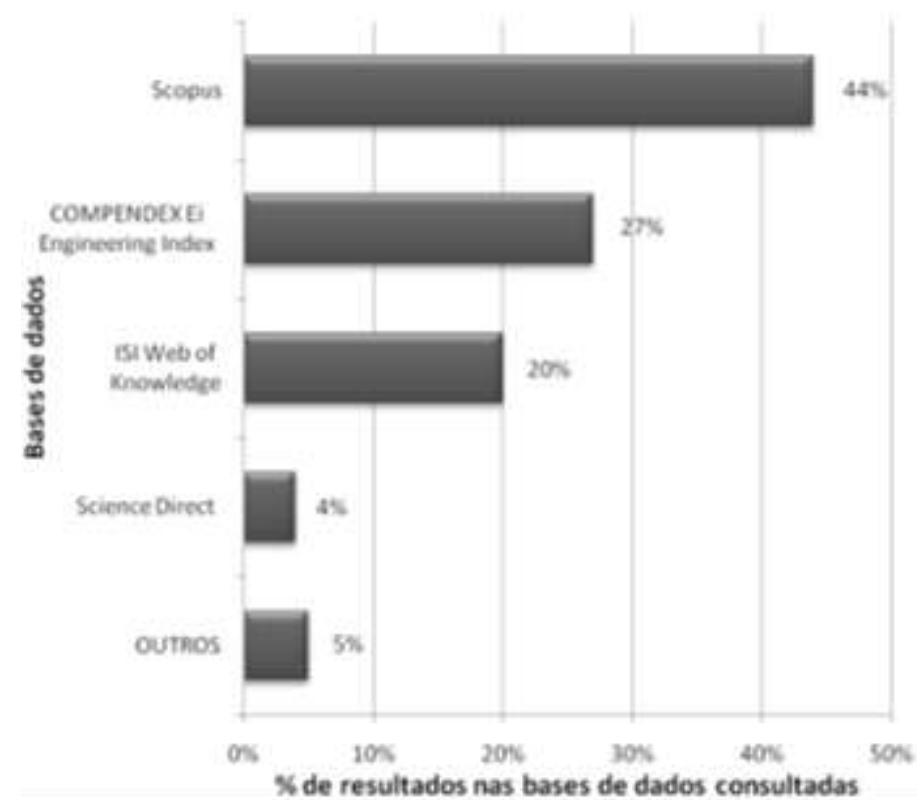

Fonte: Autoria própria (2008)

Nas quatro bases de dados restantes (Web of Science, Science Direct, Scopus e COMPENDEX Ei Engineering Index) pesquisou-se com combinações de palavras-chave selecionadas pelos pesquisadores. Essas combinações foram determinadas fixando-se as duas palavras-chave ("Research and Development" e "Evaluation") que, pelo julgamento dos pesquisadores, são as mais importantes. Combinando-se essas duas palavras às três palavras-chave restantes ("performance measurement", "project selection" e "decision-making") definiu-se as combinações de palavras-chaves utilizadas para realizar a pesquisa nas bases de dados selecionadas. O objetivo de definir essas três combinações de palavras-chave foi reduzir e focalizar os resultados para o tema de pesquisa. Os resultados numéricos, assim como as combinações estão exemplificados na Tabela 2.

Tabela 2 - Resultados da pesquisa com as combinações de palavras-chave

\begin{tabular}{|c|c|c|c|c|}
\hline & Filtro Utilizado & $\begin{array}{c}\text { "Research and } \\
\text { Development" } \\
\text { "Evaluation" } \\
\text { "performance } \\
\text { measurement" }\end{array}$ & $\begin{array}{c}\text { "Research and } \\
\text { Development" } \\
\text { "Evaluation" } \\
\text { "project } \\
\text { selection"” }\end{array}$ & $\begin{array}{c}\text { "Research and } \\
\text { Development" } \\
\text { "Evaluation" } \\
\text { "decision- } \\
\text { making"” }\end{array}$ \\
\hline Engineering Village & $\begin{array}{c}\text { Subject, title, } \\
\text { abstract }\end{array}$ & 10 & 6 & 66 \\
\hline Science Direct & $\begin{array}{c}\text { Title, abstract, } \\
\text { keywords }\end{array}$ & 2 & 1 & 48 \\
\hline Scopus & $\begin{array}{c}\text { Title, abstract, } \\
\text { keywords }\end{array}$ & 15 & 11 & 4 \\
\hline
\end{tabular}




\begin{tabular}{|c|c|c|c|c|}
\hline ISI Web of Knowledge & Topic & 7 & 11 & 94 \\
\hline \multicolumn{5}{|c|}{$\begin{array}{c}\text { Obs: Os filtros utilizados são explicitados, pois as Bases de Dados não permitem a realização da } \\
\text { pesquisa com o mesmo filtro. }\end{array}$} \\
\hline \multicolumn{5}{|c|}{ Excluindo artigos que contivessem as palavras: } \\
\hline \multicolumn{5}{|c|}{$\begin{array}{c}\text { physics OR mathematics OR biology OR medicine OR education OR dentistry OR arts OR tourism OR } \\
\text { security OR chemical OR chemistry OR health OR nuclear OR marketing OR space OR } \\
\text { pharmaceutical OR fuel cell OR database }\end{array}$} \\
\hline
\end{tabular}

Fonte: Autoria própria (2008)

Todas as referências indicadas na Tabela 2 foram importadas para um software de gerenciamento de citações e foram retiradas as duplicações existentes. Após a remoção das duplicações, o número total de referências caiu de 285 para 200 artigos.

Para reduzir os artigos a um grupo factível de ser trabalhado, realizou-se a leitura dos títulos e removidos os não alinhados reduzindo o grupo para 92 artigos. Com o conjunto restante, realizouse uma pesquisa no Google Acadêmico para identificar quantas citações possuía cada artigo, podendo assim, identificar quais trabalhos foram mais citados. Criou-se um diagrama de Pareto das citações dos trabalhos (Gráfico 2) e separaram-se aqueles que representavam cerca de $80 \%$ da amostra total de citações. Para os artigos não selecionados realizou-se um processo de releitura dinâmica dos títulos e resumos a fim de avaliar se algum poderia ser reagrupado aos anteriormente separados, uma vez que os artigos publicados entre 2006 a 2008, geralmente, têm menor número de citações, já que o trabalho está disponível para análise há menos tempo.

Gráfico 2 - Análise sobre o percentual de citações dos artigos pelo Google Acadêmico

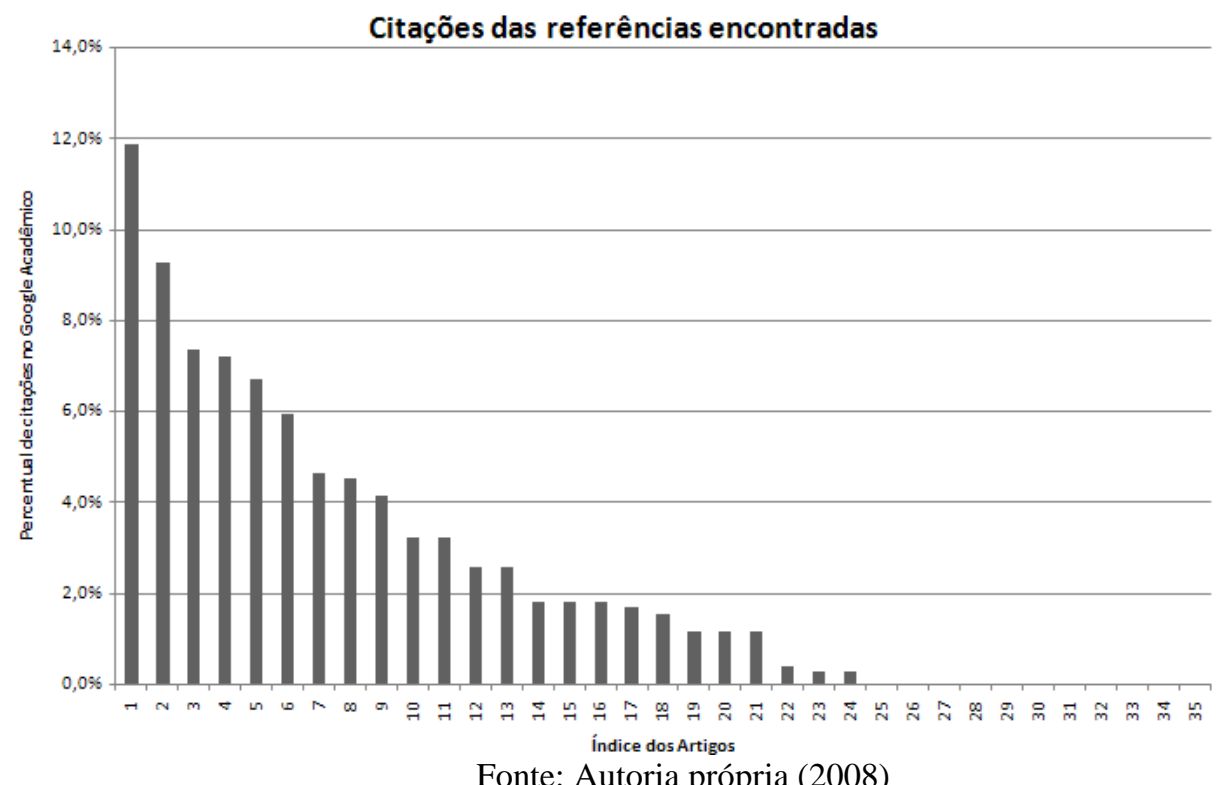

Com este processo identificou-se um conjunto de 8 artigos aos quais se denominou “enquadrados". Sendo assim, estes foram analisados e a partir dos mesmos se construiu o referencial teórico. Os artigos selecionados passaram a ser aqueles contidos na Tabela 3. 
Tabela 3 - Artigos analisados para construção do Referencial Teórico

\begin{tabular}{|c|c|c|c|c|}
\hline & Autores & Título & Ano & Periódico \\
\hline$[1]$ & $\begin{array}{c}\text { Bitman, W. and N. } \\
\text { Sharif }\end{array}$ & A conceptual framework for ranking R\&D \\
projects. & 2008 & $\begin{array}{c}\text { IEEE Transactions on } \\
\text { Engineering Management }\end{array}$ \\
\hline [2] & $\begin{array}{c}\text { Coldrick, S., } \text { et al. } \\
\text { [3] }\end{array}$ & A decision framework for R \& D project \\
selection. & 2002 & $\begin{array}{c}\text { IEngineering Management } \\
\text { Conference }\end{array}$ \\
\hline [4] & $\begin{array}{c}\text { Lee, J.W. and S.H. } \\
\text { Kim }\end{array}$ & $\begin{array}{c}\text { Integrated project evaluation and selection using } \\
\text { multiple-attribute decision-making technique. } \\
\text { programming for interdependent information } \\
\text { system project selection. }\end{array}$ & 2006 & $\begin{array}{c}\text { International Journal of } \\
\text { Production Economics }\end{array}$ \\
\hline [5] & $\begin{array}{c}\text { Meade, L.M. and } \\
\text { A. Presley }\end{array}$ & $\begin{array}{c}\text { R and D project selection using the analytic } \\
\text { network process. }\end{array}$ & 2000 & $\begin{array}{c}\text { Computers \& Operations } \\
\text { Research }\end{array}$ \\
\hline [6] & $\begin{array}{c}\text { Pillai, A.S., A. } \\
\text { Joshi, and K.S. } \\
\text { Rao }\end{array}$ & $\begin{array}{c}\text { Performance measurement of R and D projects } \\
\text { in a multi-project, concurrent engineering } \\
\text { environment. }\end{array}$ & 2002 & $\begin{array}{c}\text { International Journal of } \\
\text { Project Management }\end{array}$ \\
\hline [7] & $\begin{array}{c}\text { Shin, C.-O., S.-H. } \\
\text { Yoo, and S.-J. } \\
\text { Kwak }\end{array}$ & $\begin{array}{c}\text { Applying the analytic hierarchy process to } \\
\text { evaluation of the national nuclear R\&D projects: } \\
\text { The case of Korea. }\end{array}$ & 2007 & $\begin{array}{c}\text { Progress in Nuclear } \\
\text { Energy }\end{array}$ \\
\hline [8] & $\begin{array}{c}\text { Stummer, C. and } \\
\text { K. Heidenberger }\end{array}$ & $\begin{array}{c}\text { Interactive R\&D portfolio analysis with project } \\
\text { interdependencies and time profiles of multiple } \\
\text { objectives. }\end{array}$ & 2003 & $\begin{array}{c}\text { IEEE Transactions on } \\
\text { Engineering Management }\end{array}$ \\
\hline
\end{tabular}

Fonte: Autoria própria (2008)

\section{Referencial teórico}

Organizações que buscam inovação necessitam constantemente decidir onde serão alocados os recursos escassos disponíveis. Freqüentemente propostas para realização de projetos de P\&D nessas empresas são apresentadas e neste momento específico necessita-se escolher quais são os projetos mais adequados à organização.

Deste modo, emerge a necessidade de ter um instrumento que ajude a fazer a gestão de tal situação. Quando defrontado com situações semelhantes Sir William Thomson, Lord Kelvin assim se manifestou:

\footnotetext{
When you can measure what you are speaking about, and express it in numbers, you know something about it; but when you cannot measure it, when you cannot express it in numbers, your knowledge is of a meager and unsatisfactory kind: it may be the beginning of knowledge, but you have scarcely, in your thoughts, advanced to the stage of science. (WILLIAM THOMSON, Lord KELVIN, 1891-1894).
}

Em tais contextos a primeira preocupação está centrada na construção do conhecimento que leve a entender aquilo que se deseja gerir. Esta situação torna-se mais aguçada quando se trata de contextos nos quais as conseqüências das decisões sejam relevantes. Em tais situações é usual desejar-se conhecer quais os aspectos considerados relevantes, como medi-los individual e coletivamente. A nomenclatura científica utilizada para alcançar este propósito denomina-se avaliação do desempenho. Neste contexto, acredita-se que a definição proposta pelo LabMCDAEPS-UFSC para avaliação de desempenho (AD) se enquadre nas demandas destes ambientes decisórios: Avaliação de Desempenho é um processo para construir conhecimento no decisor, a 
respeito do contexto específico que se propõe avaliar, por meio de atividades que identificam, organizam, mensuram ordinalmente e cardinalmente, integram e permitem visualizar o impacto das ações e seu gerenciamento, a partir da percepção do próprio decisor (ENSSLIN, L. et al., 2010; LACERDA; ENSSLIN; ENSSLIN, 2011).

Neste contexto, buscou-se na literatura artigos na área de avaliação e seleção de projetos de $P \& D$ que oferecem subsídios para o alcance das etapas apresentadas na definição de avaliação de desempenho adotada para o trabalho. A pesquisa selecionou, conforme processo apresentado na Tabela 3, uma amostra representativa no que se refere à adequação ao tema pesquisado. Para esse conjunto de oito artigos relativos ao tema que se deseja fazer gestão, definiu-se um processo de análise de modo que se evidenciassem os aspectos essenciais para o conceito de avaliação de desempenho adotada anteriormente.

Deste modo, a análise dos artigos foi realizada em termos do conceito de avaliação de desempenho adotada no trabalho e verificando se as ferramentas utilizadas identificam, mensuram e integram os critérios do contexto. Também se avaliou os estudos de caso e tendências verificadas nos artigos.

\section{a) Conceito de AD adotados pelos autores}

A primeira análise feita diz respeito ao que cada autor entendia por avaliação de desempenho. Desta forma, pode-se observar que três de oito artigos - Meade e Presley (2002), Dey (2006), Bitman e Sharif (2008) - utilizaram-se da identificação de critérios e subcritérios, comparação aos pares, definição de pesos e hierarquização como itens de sua avaliação de desempenho. Para Pillai et al. (2002) o importante seria refletir sobre as necessidades e expectativas dos Stakeholders, reavaliar os pressupostos assumidos no passado e utilizar uma abordagem integrada de forma a prever sucesso ou fracasso dos projetos em tempo hábil. Percebe-se que esses autores consideram relevante a identificação e representação dos critérios considerados importantes pelos decisores.

A avaliação de desempenho para Stummer e Heidenberger (2003) é realizada pela maximização de uma função objetivo-linear obtida pela soma linear dos benefícios de cada projeto constante no portfólio. Já para Shina et al. (2007) a avaliação é a investigação e comparação dos resultados dos projetos de $\mathrm{P} \& \mathrm{D}$ no momento de sua conclusão, mensurando assim os efeitos das atividades de P\&D. Lee e Kim (2000) não apresentam de forma explícita o conceito de avaliação de desempenho, entretanto poderia ser inferido que a avaliação é realizada por alguma soma ponderada das performances nos critérios. Por último, a avaliação de acordo com Coldrick et al. (2002) é realizada por meio de um modelo compensatório, onde são incorporadas as etapas de pontuação, análise de riscos e análise financeira.

Em linhas gerais verifica-se que a convergência dos autores está na identificação de uma 
valoração final e na possibilidade de comparação do desempenho em instantes diferentes. Sendo assim, metade dos artigos preocupa-se com a investigação das necessidades do contexto, a outra metade preocupa-se em obter um resultado "numérico", a avaliação propriamente dita. A partir dessa análise é possível inferir que os quatro primeiros trabalhos estão alinhados à definição de AD adotada no presente estudo.

\section{b) Identificação dos critérios}

Na segunda parte, a análise foi realizada a partir das ferramentas utilizadas nos artigos da amostra. No que diz respeito à identificação de critérios, notou-se que em quatro dos oito artigos analisados, estes são assumidos como pré-existentes, ou seja, as ferramentas não apresentam um processo estruturado para identificar quais critérios são importantes no contexto decisório, evidenciando um aspecto de possível aperfeiçoamento para as ferramentas analisadas. Para tais artigos os objetivos foram identificados por meio de pesquisa na literatura, consulta a especialistas, professores e experiências em programas de avaliação e seleção de P\&D.

Dentre os quatro artigos que desenvolveram a questão da identificação dos critérios, no artigo de Pillai et al. (2002) a identificação é feita por meio da análise das necessidades e expectativas dos Stakeholders, contudo não explicita como isto é realizado. Para Bitman e Sharif (2008) os critérios são identificados por meio de busca na literatura, estes critérios identificados passam, posteriormente, por avaliações de pessoas diretamente envolvidas na escolha de projetos em P\&D. Já para Dey (2006) os critérios são identificados por meio de entrevistas com os decisores. Para Shina et al. (2007) os critérios foram identificados através de pesquisa na literatura, consulta a especialistas, professores e análise das experiências vividas em programas de avaliação de P\&D.

Nota-se assim, que as ferramentas carecem de um procedimento para identificação dos critérios ad hoc. Percebe-se então um aspecto a ser melhorado nas ferramentas analisadas, pois a primeira etapa necessária para se conhecer algo, segundo o conceito de AD adotado, é identificar quais são os aspectos julgados importantes no contexto decisório. Caso contrário pode-se estar avaliando determinada situação desconhecendo alguns dos aspectos importantes nessa avaliação.

\section{c) Mensuração dos critérios}

Na terceira etapa da análise, a mensuração dos critérios, para quatro dos oito artigos (Shina et al. (2007), Lee e Kim (2000), Meade e Presley (2002), Dey (2006)), é feita por meio da hierarquização das alternativas previamente estabelecidas, expressas por escalas ordinais. $\mathrm{Na}$ metodologia AHP e/ou ANP, em um primeiro momento, a construção das escalas é feita na forma ordinal e em um segundo momento por meio de julgamentos do decisor, incorporando-se a diferença de atratividade com questionamentos de relacionamentos de proporcionalidade, o que é 
válido somente se as escalas forem de razão.

Outros três artigos utilizam diferentes métodos para mensurar os critérios identificados. Para Stummer e Heidenberger (2003) os critérios são selecionados de forma a que sejam numéricos (alfa-numéricos) e o seu valor é utilizado para representar a intensidade de seu uso. O seu grau de alcance será determinado em função da soma das contribuições daqueles projetos que fizerem parte do portfolio.

No artigo de Coldrick et al. (2002) mensura-se critérios valendo-se de uma escala de 1 a 5 para pontuar cada critério. Já para Pillai et al. (2002) não são construídas escalas para os critérios. Utilizam-se de um score, porém não explicitando como este é definido. Para cada projeto, a pontuação é dada pela soma da pontuação dos fatores de sucesso, e a pontuação dos fatores de sucesso é dada pela média dos pesos multiplicados pelos scores de cada critério.

Para Bitman e Sharif (2008), a mensuração é realizada alocando em cada critério as alternativas segundo seu desempenho. Inicialmente a escala é ordinal e é transformada em cardinal sem identificar níveis de referência.

Nota-se que, com relação à mensuração, a suposição de que as escalas utilizadas sejam de razão é inconsistente uma vez que a transformação das mesmas para escalas de razão, definindo níveis referenciais, não é realizada.

\section{d) Integração dos critérios}

Na quarta etapa da análise, a integração dos critérios, percebe-se que a maioria, com exceção de um artigo, faz a integração de forma indireta identificando pesos que permitem assim obter uma pontuação global.

A integração dos critérios no artigo de Stummer e Heidenberger (2003) é realizada de maneira linear, valendo-se de uma função objetivo. A integração é realizada pela soma dos benefícios de cada projeto em cada uma das propriedades identificadas como restritiva ou demandante. É utilizado um fator para converter unidades de cada benefício em unidades globais.

Para oferecer melhor visualização da análise realizada nas ferramentas explicitadas nos artigos, construiu-se a figura 1, explicitando quais artigos continham nas ferramentas utilizadas etapas para identificar, mensurar e integrar os aspectos julgados importantes no contexto decisório. Apesar de a classificação englobar todas as ferramentas nos itens mensuração e integração, relembra-se das limitações avaliadas nas mesmas, com relação à mensuração a suposição de que as escalas sejam de razão é inconsistente. No que se refere à integração, os métodos que a fazem de maneira indireta podem se tornar vulneráveis a medida que os extremos das escalas sofram modificações. Problema conhecido como "rank reversal order".

\section{e) Realização do "Gerenciamento" nas ferramentas utilizadas}


Analisando o gerenciamento das ferramentas da amostra, todas apresentaram algum tipo de gerenciamento, mesmo que não estruturado. Para Lee e Kim (2000), o gerenciamento é realizado por meio da seleção de projetos de acordo com critérios e restrições previamente estabelecidas. Para Meade e Presley (2002), Coldrick et al. (2002), Stummer e Heidenberger (2003) e Shina et al. (2007) o gerenciamento é realizado de uma maneira geral analisando-se a pontuação de cada alternativa em termos globais e em cada critério individualmente, permitindo verificar o desempenho em cada critério. Para Dey (2006), o gerenciamento é feito de acordo com a avaliação global fornecida pelo modelo, sendo que este melhora a comunicação entre os stakeholders e possibilita a avaliação e seleção de projetos de que são desenvolvidos. Para Bitman e Sharif (2008) o gerenciamento é primordialmente realizado na avaliação global, uma vez que os desempenhos de cada alternativa em cada critério fornecem apenas a informação da sua ordem hierárquica em relação às demais.

Apesar de o gerenciamento ser feito por todas as ferramentas utilizadas, estas não são capazes de organizar os critérios, não os apresentando numa escala de ordem de preferência, ou seja, a adição de qualquer outro critério mudaria quase que por inteiro a organização préestabelecida antes que este critério fosse acrescentado. Um segundo ponto falho é o fato de estas ferramentas não permitirem um gerenciamento que abranja desde questões operacionais, passando por questões táticas e atingindo as estratégicas.

Figura 1 - Enquadramento das ferramentas analisadas segundo os critérios: Identificação, mensuração, integração e gerenciamento

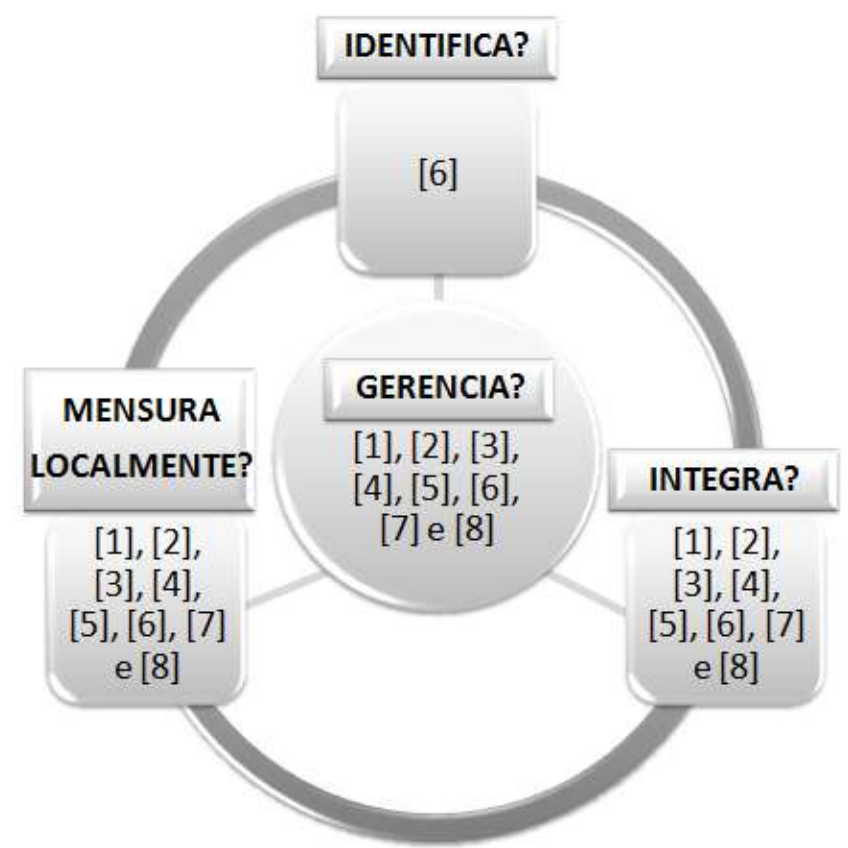

Fonte: Autoria própria (2008)

Assim, nota-se de uma maneira geral, que os autores pouco se preocupam em identificar, mensurar, integrar e gerenciar os critérios simultaneamente. Com relação à identificação, percebe-se 
que quando existe a preocupação em identificar os objetivos, a ferramenta carece de um processo estruturado para desenvolvimento de tal etapa. Em relação à mensuração, apesar de todas as ferramentas realizarem estas etapas, o fazem de maneira parcial, uma vez que negligenciam a transferência das escalas ordinais em cardinais. A mensuração é realizada, nos métodos AHP e ANP, pressupondo que as escalas construídas são de razão, o que nem sempre ocorre. A integração, de maneira geral, é realizada de maneira indireta fazendo com que os modelos possam apresentar avaliação diferente ao serem modificas as alternativas como citado anteriormente.

\section{f) "Estudos de caso e tendências verificadas"}

O primeiro aspecto verificado nesta etapa foi o desenvolvimento, ou não, de um estudo de caso nos artigos da amostra. Em caso afirmativo, primeiramente, analisou-se como se fez a implementação da ferramenta, se esta era utilizada na íntegra, ou se havia a necessidade de algum tipo de incorporação. Em um segundo momento, foi feita a análise das vantagens e desvantagens de cada ferramenta.

Apenas dois artigos - Shina et al. (2007) e Meade e Presley (2002) - abordam o tema de seleção de projetos de P\&D na forma de estudo de caso. Shina et al. (2007) mostra como o AHP pôde auxiliar o Governo da Coréia na seleção de projetos de P\&D nucleares. Nenhuma limitação da ferramenta foi citada no estudo. Apenas outras indicações para a utilização da mesma em demais áreas da seleção de P\&D. Entretanto, nota-se que a avaliação é realizada em um primeiro momento para mensurar o desempenho das alternativas em cada critério previamente definido. Tal avaliação pressupõe que a escala seja de razão. No entanto isto raramente acontece. Em um segundo momento, a avaliação é realizada quando da definição dos pesos, o que é feito em termos da comparação da contribuição de cada critério. Cada critério é mensurado pelo impacto no mesmo das alternativas existentes.

Para Meade e Presley (2002), o objeto de estudo foi uma pequena empresa high-tech nos Estados Unidos, a qual se fez do ANP para trabalhar a seleção de projetos de P\&D. O modelo usado neste estudo de caso não considera todos os possíveis critérios e tão pouco explora todas as possíveis interações com o decisor para analisar a possibilidade de dependência entre os critérios. A definição da hierarquia nas escalas também fica prejudicada devido à falta de interação do decisor. Além disso, pouco explora o efeito da incorporação de novas alternativas nas taxas. Isso limita as conclusões a respeito dos resultados finais da ferramenta utilizada.

Os demais artigos não contextualizaram o uso de suas ferramentas em um estudo prático, o que permitiu aos autores julgarem apenas as vantagens e desvantagens apresentadas pelas ferramentas em questão. Stummer e Heidenberger (2003) trabalharam com a Programação Linear Hard e mostraram que a ferramenta utilizada permite selecionar, dentre um conjunto de projetos fixos com benefícios fixos e para um conjunto de recursos estabelecidos, o conjunto de portfolios 
que irá representar o maior benefício possível e utilizar a análise de sensibilidade destes benefícios para visualizar as suas conseqüências globais. Entretanto, a determinação dos benefícios não é analisada no artigo, a associação de uma escala a cada benefício igualmente não é realizada e a transformação de um benefício i $(i=1,2,3 \ldots n)$ em alguma unidade global não é explicitada, o que dificulta a compreensão. Além disso, os benefícios simplesmente são adicionados e não estruturados.

Coldrick et al. (2002) utilizaram-se da MCDA compensatória para mostrar que a seleção de projetos de $\mathrm{P} \& \mathrm{D}$ pode ser um processo simples e rápido. Porém deixaram a desejar no momento que partiram do pressuposto que os critérios e as alternativas são pré-definidas, utilizaram-se de escalas de Lickers como cardinais, as quais são escalas ordinais, além do uso de pesos em detrimento de taxas de compensação.

Quando da utilização do MCDM por Bitman e Sharif (2008) nota-se que, apesar do método ser completo a partir da definição de AD adotada, apresenta oportunidades de aperfeiçoamento. A identificação e a construção de escalas cardinais não são feitas de forma clara. Assim, não se apresenta um processo para identificar critérios e suas escalas definem os possíveis níveis de desempenho de maneira genérica. Também apresenta o processo de integração feito por pesos. Ao determinar os pesos dos critérios sem a explicitação da escala e sem seus níveis de referência estes ficam comprometidos (KEENEY, 1992, p. 147).

Pillai et al. (2002), pela Integrated Perfomance Measurement, não explicitaram o processo de identificação das necessidades e expectativas dos stakeholders, tornando o método vulnerável, suscetível à realização dessa etapa de maneira insuficiente, pela falta de estruturação e padronização do mesmo.

Em linhas gerais percebe-se que os estudos apresentam uma carência no que diz respeito, principalmente, à fase de Estruturação (ver figura 2), aqui representada pelas etapas de identificação e construção das escalas ordinais. A grande maioria não apresenta uma forma estruturada do problema, parte de critérios previamente definidos e com métodos de mensuração que podem ser melhorados, já que em todos os casos analisados a avaliação é feita por pesos e não por taxas de compensação.

A fim de verificar quais são as vantagens e desvantagens explicitadas nas ferramentas utilizadas, criou-se uma tabela 4.

Tabela 4 - Análise das tendências verificadas nos artigos

\begin{tabular}{|c|c|}
\hline Autor & Tendências observadas \\
\hline $\begin{array}{c}\text { Jin Woo Lee, Soung } \\
\text { Hie Kim - 2000 }\end{array}$ & $\begin{array}{l}\text { Usando ferramentas combinadas (método proposto) os autores concluíram que é possível } \\
\text { resolver problemas de múltiplos critérios, interdependência e restrição de recursos. }\end{array}$ \\
\hline
\end{tabular}




\begin{tabular}{|c|c|}
\hline $\begin{array}{l}\text { S. Coldrick, C.P. } \\
\text { Lawson P. C. Ivey and } \\
\text { C. Lockwood - } 2002\end{array}$ & $\begin{array}{l}\text { Os autores mostraram que a utilização de ferramentas combinadas leva a uma melhor } \\
\text { qualidade da seleção de portfólio, além da habilidade em incluir dados qualitativos e } \\
\text { quantitativos. }\end{array}$ \\
\hline $\begin{array}{c}\text { Laura M. Meade e } \\
\text { Adrien Presley - } 2002\end{array}$ & $\begin{array}{l}\text { Através do ANP os autores obtiveram um valor numérico para cada alternativa o que } \\
\text { permitiu identificar a mais apropriada. Esta pontuação foi fruto das informações de } \\
\text { comparações dos impactos das alternativas nos critérios e seus pesos. (avaliação local) }\end{array}$ \\
\hline $\begin{array}{l}\text { A. Sivathanu Pillai, A. } \\
\text { Joshi e K.Srinivasa Rao } \\
\quad-2002\end{array}$ & $\begin{array}{l}\text { Os autores alertam para a necessidade de ter em conta os atores envolvidos no problema. } \\
\text { Avaliam os projetos de maneira integrada, considerando as fases de seleção } \\
\text { (identificação, avaliação e seleção), execução (desenvolvimento de tecnologia, } \\
\text { desenvolvimento do produto e prototipagem) e implementação (Produção, marketing e } \\
\text { vendas). O modelo quantificou e integrou os fatores críticos de sucesso (critérios) para } \\
\text { um indicador único. }\end{array}$ \\
\hline $\begin{array}{l}\text { Christian Stummer and } \\
\text { Kurt Heidenberger - } \\
2003\end{array}$ & $\begin{array}{l}\text { Os autores mostraram como utilizar ferramentas de pesquisa operacional para gerenciar } \\
\text { projetos de } P \& D \text { em contextos onde o entendimento permitiu identificar um número muito } \\
\text { grande de alternativas assim como os principais benefícios de cada um. }\end{array}$ \\
\hline $\begin{array}{l}\text { Prasanta Kumar Dey - } \\
2006\end{array}$ & $\begin{array}{l}\text { Os autores integraram os critérios para a escolha do melhor projeto. Por meio do AHP, } \\
\text { obtiveram um valor numérico para cada alternativa o que permitiu identificar a mais } \\
\text { apropriada. Esta pontuação é fruto das informações de comparações dos impactos das } \\
\text { alternativas nos critérios e seus pesos. }\end{array}$ \\
\hline $\begin{array}{l}\text { Chul-Oh Shina, Seung- } \\
\text { Hoon Yoob and Seung- } \\
\text { Jun Kwakc - } 2007\end{array}$ & $\begin{array}{l}\text { Os autores melhoraram os procedimentos de avaliação do National Nuclear R\&D, } \\
\text { tornando possível o entendimento global das estratégias dos projetos de P\&D e } \\
\text { padronizando o processo de avaliação dos mesmos, evitando julgamentos implícitos e } \\
\text { subjetivos. } \\
\text { A forma de representação dos critérios permitiu ativa participação dos avaliadores dos } \\
\text { projetos. Os resultados foram transparentes e de fácil compreensão por parte dos } \\
\text { envolvidos. }\end{array}$ \\
\hline $\begin{array}{l}\text { William R. Bitman, e } \\
\text { Nawaz Sharif - } 2008\end{array}$ & $\begin{array}{l}\text { Os autores adotam uma abordagem múltiplos critérios, melhorando a qualidade e } \\
\text { abrangência do modelo. Apresentam um gráfico que pode ajudar a orientar o } \\
\text { enquadramento do futuro projeto. Por meio deste gráfico a empresa pode visualizar } \\
\text { onde sua competitividade possui um nível abaixo do esperado e tomar decisões para a } \\
\text { seleção dos projetos. }\end{array}$ \\
\hline
\end{tabular}

Fonte: Autoria própria (2008)

Averigua-se com os itens destacados no texto acima juntamente com as análises realizadas nas seções 3.a, 3.b, 3.c e 3.d, a necessidade de avaliar o problema de P\&D adotando métodos qualitativos e quantitativos que permitissem um entendimento global. Nesses problemas, a identificação destes critérios também é citada. Além disso, em todos os artigos analisados os problemas são de múltiplos critérios. Nota-se adicionalmente que a utilização de uma estrutura hierárquica facilitou o entendimento dos decisores e tornou os resultados transparentes. Percebeu-se também a importância em obter-se uma pontuação local e global pelos itens destacados nos modelos. Nesse contexto, a integração dos fatores pode ser evidenciada, pois ela leva ao alcance de um indicador único de desempenho do modelo global. Finalmente, a necessidade implícita nas tendências verificadas é a necessidade de gerenciar com números o problema do contexto.

Assim, estes aspectos citados acima são de grande importância na escolha do método mais adequado para fazer a avaliação e o gerenciamento nos contextos complexos decisórios.

\section{Metodologia da pesquisa: a Metodologia Multicritério de Apoio à Decisão Construtivista}




\section{(MCDA-C)}

Para atender a pergunta da pesquisa a metodologia para avaliar contextos complexos e multicritério necessita de pelo menos as fases de estruturação, avaliação e recomendações, como exemplificadas pela figura 2 .

Figura 2 - Fases do apoio à decisão

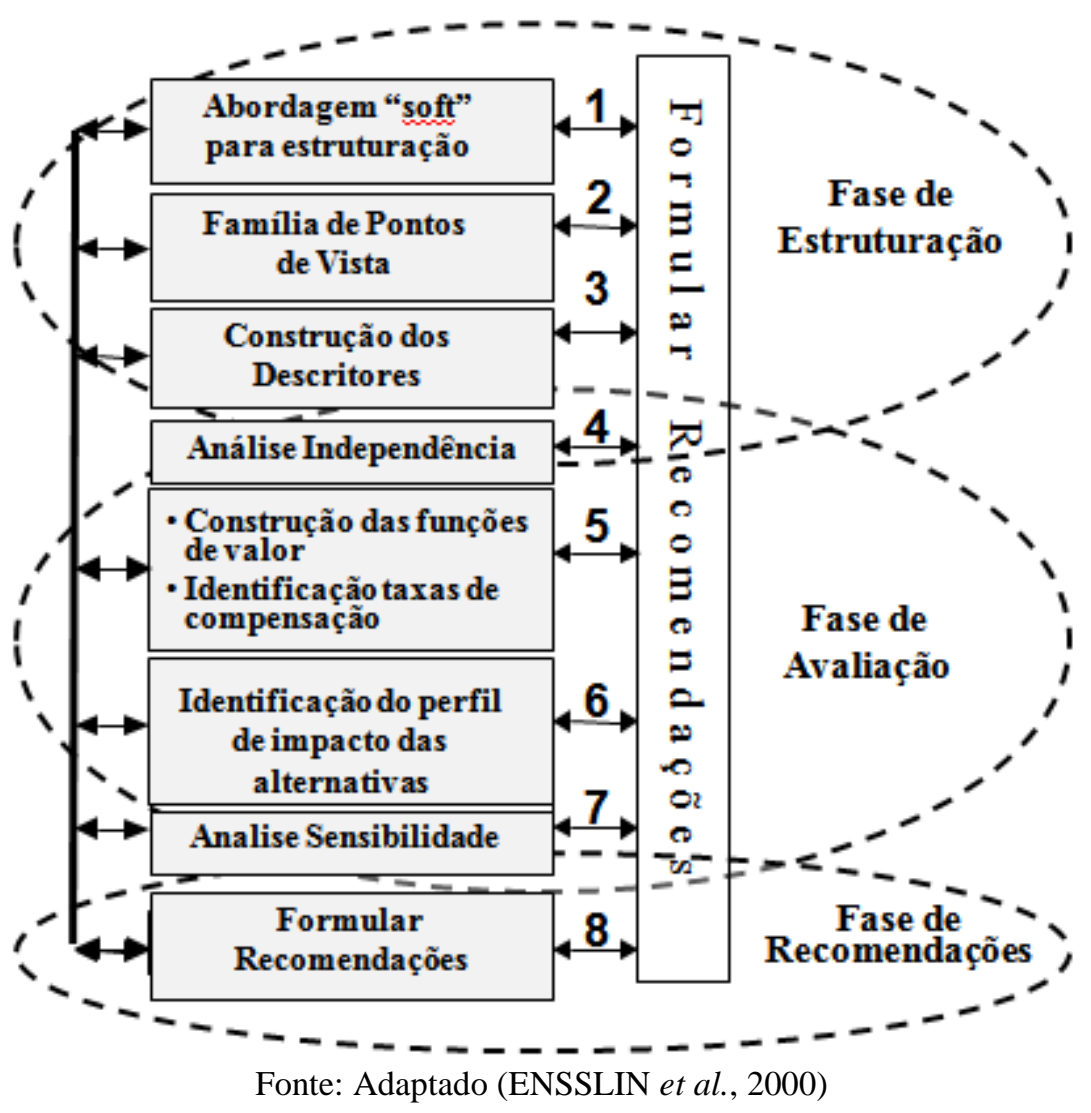

\section{a) Fase de estruturação}

A primeira fase, Estruturação, é subdividida em: contextualização, construção de mapas cognitivos, análise dos mesmos, criação de famílias de pontos de vista fundamentais e elaboração de árvores de valor (ENSSLIN et al., 2001).

A contextualização do problema engloba algumas definições:

- Identificação do contexto decisório: aspectos que devem ser definidos para a personalização do processo decisório;

- Atores da situação: englobam todos os indivíduos envolvidos direta ou indiretamente no processo decisório. São aqueles que, influenciam e/ou são influenciados pelo contexto decisório. Podem ser subdivididos em: decisor (aquele que assume as conseqüências das decisões) intervenientes (aqueles que participam diretamente do processo decisório, mas não lhes cabe a decisão final ), agidos (aqueles que participam de forma indireta), e facilitador (aquele que tem como função ajudar aos atores a melhor entender as conseqüências de suas decisões em seus 
valores);

- Criação de um rótulo: nome que traduz o problema discutido. Sua criação não é definitiva, logo, ele pode e deve ser alterado conforme o entendimento do problema evolua;

- Sumário: descrição do problema em texto corrido respondendo às perguntas: qual é o problema, qual sua importância, qual o objetivo do trabalho, quais as propostas para alcançar tal objetivo (instrumento de intervenção) e, finalmente, quais os resultados esperados.

Finalizando a contextualização, dá-se início à construção dos mapas cognitivos. A primeira etapa deste processo é a definição dos Elementos Primários de Avaliação (EPA's) os quais são elaborados a partir de um brainstorming com o decisor. Esses elementos (Bana e Costa, 1999) são constituídos de objetivos, metas, valores dos decisores, além de ações, opções e alternativas.

O próximo passo é a construção de conceitos a partir dos EPA's. Cada EPA origina um ou mais conceitos. O conceito expressa a direção de preferência associada ao EPAs acompanhado da motivação para sua existência. Tal processo é realizado colocando o verbo de cada EPA no infinitivo, logo, o conceito tem caráter de ação. Após isso se torna necessário definir o pólo oposto psicológico que nada mais é que um complemento ao conceito, partindo do princípio que um conceito só pode ter sentido quando existe um contraste entre dois pólos (EDEN et al., 1983). O conceito e seu pólo oposto são separados por “...”, lido como "ao invés de”. O texto de cada conceito recomenda-se não exceder 12 palavras, buscando sempre manter palavras e frases já ditas pelo decisor o que torna a discussão singular.

Segue-se para a organização dos conceitos em relações de causa e efeito, denominadas mapas cognitivos, e para a construção de uma hierarquia na qual os conceitos passam a ser divididos entre conceitos meios e conceitos fins, relacionados por ligações de influências.

Seguindo neste raciocínio, dividem-se os mapas em clusters que seriam um conjunto de nós relacionados de forma muito forte. Assim, cada cluster pode ser analisado como um mapa independente com complexidade reduzida.

Para cada cluster associa-se um "rótulo" que representará o conjunto de relações de influência do mapa cognitivo. Estes então são transferidos para uma estrutura arborescente onde estarão representados os PVF's e os PVE's. Esta representação se vale de uma estrutura hierárquica de decomposição para representar os valores e preferências do(s) decisor(es).

Os PVE vão sendo decompostos até que algum deles represente uma propriedade objetiva passível de ser mensurada. A estrutura de decomposição cessa e emerge então uma escala para medir a performance da propriedade associada a preocupação subjetiva do PVE. Esta escala ordinal é denominada “descritor". Este é o maior volume de conhecimento qualitativo que se pode construir do contexto segundo a percepção dos atores envolvidos. Para aprofundar o conhecimento necessitase transformar estas escalas ordinais em cardinais aumentando a precisão do conhecimento. Está é a 
fase seguinte da metodologia MCDA-C conhecida como "Avaliação".

\section{b) Fase de avaliação}

Na fase de Avaliação o decisor passará a ter uma visão cardinal do contexto. Para tanto será desenvolvido um modelo matemático para ajudar aos atores a incorporar seus valores e preferências ao contexto. Este processo tem como objetivo incorporar os juízos de valor preferencial dos atores propiciando-lhes as condições para medir o valor da situação atual e das ações construídas a partir deste conhecimento.

Para se conseguir chegar a uma avaliação global é necessário construir funções de valor que, segundo Ensslin et al. (2001, p. 187), “é um instrumento para auxiliar os decisores a expressar, de forma numérica, suas preferências."

Como as funções são utilizadas para ordenar a intensidade de preferência entre as ações, os descritores devem estar em ordem de preferência para o decisor. Deste modo, organizam-se os descritores numa forma matricial, utilizando o conceito de Matriz de Roberts (QUIRINO, 2002; AZEVEDO, 2001) que ordena os níveis dos descritores pela preferência expressada pelo decisor.

Para construir as funções de valor optou-se por utilizar o método do julgamento semântico, onde a função de valor é obtida através de comparações par-a-par da diferença de atratividade entre ações potenciais (BEINAT, 1995 apud ENSSLIN et al., 2001). Tais comparações, segundo Ensslin et al. (2001, p. 195), são feitas solicitando que os decisores expressem qualitativamente a intensidade de preferência de uma ação sobre a outra. Para o presente trabalho utilizou-se do software MACBETH (Measuring Attractiveness by a Categorical Evaluation Technique), desenvolvido por Bana e Costa e Vansnick (1995), para auxiliar no processo de julgamento do decisor em relação à diferença de atratividade entre as alternativas.

As funções de valor representam matematicamente as diferenças de atratividades entre os diferentes níveis de desempenho de cada descritor para o decisor. Portanto, as escalas representam, numericamente, quanto para o decisor um nível de impacto é mais atrativo em relação a outro. Para este trabalho as funções de valor possuem as propriedades de uma escala de intervalos. Estas escalas, segundo Ensslin et al. (2001, p. 208), além de classificar e ordenar, tem como função distinguir a diferença de magnitude entre as categorias. As escalas de intervalo, utilizadas neste trabalho, permitem que o decisor expresse através de números a preferência de um nível em relação a outro, uma vez que o intervalo existente entre esses dois números pode ser comparado com outro intervalo, ambos ancorados em níveis de referência (KEENEY, 1992, p. 147).

Neste ponto é possível apenas realizar a avaliação local do desempenho das ações, ou seja, em cada critério. Para se ter uma avaliação global, isto é, fazer com que uma mudança de desempenho em um descritor possa ser comparada com mudanças de desempenho em outros descritores, constrói-se as Taxas de Substituição que, segundo Ensslin et al. (2001, p. 218), são 
como constantes de escala, que transformam valores locais de preferência (avaliados em cada critério) em valores globais. Desta forma, cada critério é representado por uma taxa de substituição que é a importância relativa que um descritor tem em relação a outros, comparando-os através dos níveis de referência "Bom" e "Neutro". Tais taxas, quando combinadas, levam a uma avaliação global que permite ao decisor comparar as alternativas disponíveis. Um dos métodos que podem ser utilizados para a obtenção das taxas é o da Comparação Par-a-Par, análogo ao citado anteriormente (Julgamento Semântico), o qual também utiliza a lógica MACBETH. Assim, para a elaboração das taxas de substituição, apenas dois critérios são julgados por vez. Deste modo criam-se três alternativas com as diferentes opções de performances. Ou seja, a primeira alternativa (A1) possui nível de impacto Bom no primeiro critério e Neutro no segundo; na segunda alternativa (A2) ocorre o inverso sendo que o primeiro critério possui nível de impacto Neutro e o segundo possui nível Bom. Ainda para este método existe a criação de uma terceira alternativa (A0) que serve como ancoragem, onde o nível Neutro se aplica nos dois critérios.

Após a criação das alternativas deve-se ordená-las de acordo com a preferência, podendo-se utilizar novamente a Matriz de Roberts para a ordenação. Por fim, para determinar as taxas de substituição, faz-se necessário um novo julgamento semântico para saber a diferença de atratividade entre uma alternativa existente e outra. De tal modo, são obtidas as taxas de substituição que possibilitam uma visão global para ajudar o decisor a construir o entendimento e, portanto, melhor comparar as opções disponíveis.

A principal diferença entre as taxas de substituição e os "pesos" utilizados por todos os modelos analisados na literatura é que as taxas são obtidas pela comparação Par-a-Par dos critérios de avaliação analisando-se níveis de referência previamente estabelecidos ("Bom" e "Neutro"). Assim, as taxas de substituição não ficam vulneráveis com a inserção de novas alternativas e/ou novos níveis de desempenho na escala construída, pois a taxa foi definida para um intervalo determinado na escalas de avaliação.

\section{c) Fase de recomendação}

Realizada a estruturação do modelo e obtida suas taxas de compensação, é possível agora avaliar o desempenho do conjunto de ações potenciais.

Após a avaliação local das ações potenciais, realizada na fase de Avaliação, é utilizada esta informação para comparar tais ações e determinar seus pontos fracos e fortes (ENSSLIN et al. 2001, p. 241). Assim, traçando seu perfil de impacto (ENSSLIN et al., 2010) é possível comparar o conjunto de ações e, a seguir, fornecer subsídios ao decisor para que este tenha condições de avaliar e selecionar qual a estratégia mais adequada a ser tomada.

Nesta fase, é possível também a realização da análise de sensibilidade, verificando-se qual 
seria o impacto possível por meio de uma variação no nível de desempenho de determinados descritores, auxiliando assim, na tomada de decisão referente a quais ações seriam realizadas.

\section{Resultados}

O estudo desenvolvido trata da avaliação e seleção de projetos de Pesquisa e Desenvolvimento (P\&D) numa empresa distribuidora de energia. A metodologia utilizada atualmente para selecionar os projetos de Pesquisa e Desenvolvimento (P\&D) na empresa é realizada da seguinte maneira: pesquisadores desenvolvem trabalhos na área de atuação da empresa e os apresentam com o intuito de serem aplicados. A empresa, por sua vez, analisa tais pesquisas de acordo com a viabilidade de implementação e necessidade de mercado, priorizando os projetos e, em seguida, capta recursos para o desenvolvimento dos mesmos.

A proposta desse estudo é criar um modelo a partir da MCDA-C que possibilite à empresa identificar os objetivos que a área de P\&D almeja operacionalizando-os via indicadores de desempenho e escalas de intervalo e integrando-os para permitir ter uma mensuração global. A partir deste conhecimento, explicitar o quanto dos objetivos a empresa já alcançou e construir ações novas e originais para melhorar mais ainda seu alcance. Estas novas ações competiriam com as existentes. Este processo propiciaria mais foco e coerência aos esforços de pesquisa e de resultados para a empresa.

Como já exposto, a metodologia utilizada, MCDA-C, é dividida em três fases: estruturação, avaliação e recomendações. Ao final de cada fase, uma apresentação foi feita ao decisor da empresa a fim de que o mesmo pudesse entender a construção, expor suas críticas e validar o modelo. Sendo uma metodologia interativa, tais apresentações foram de suma importância para a construção do conhecimento sobre o contexto.

\section{a) Fase de estruturação}

A fase de Estruturação teve início com a contextualização do problema. Assim foi identificado o contexto decisório, que, no presente trabalho, refere-se ao confronto entre uma metodologia já utilizada pela empresa para priorização de seus projetos de P\&D e uma nova, a Metodologia Multicritério de Apoio à Decisão-Construtivista (MCDA-C).

Os atores do contexto, neste caso, foram: diretor da área de P\&D da empresa, assumindo papel de decisor do presente estudo; seus colaboradores, parceiros financiadores, executores dos projetos de $\mathrm{P} \& \mathrm{D}$ além dos autores das pesquisas, aqui nomeados facilitadores. $\mathrm{O}$ grupo dos agidos foi constituído pelo mercado consumidor de gás natural e a sociedade como um todo e, como facilitadores estavam os autores do presente artigo.

Assim, o rótulo foi definido como: Modelo Multicritério de Avaliação e Seleção de Projetos de Pesquisa e Desenvolvimento em uma empresa distribuidora de energia. 
O sumário:

As empresas vinculadas a área de geração e distribuição de energia pela notável evolução tecnológica da área necessitam continuamente aperfeiçoar seus processos, produtos e mercados para compatibilizar-se com as inovações do mercado. Para melhor atender essas necessidades, essas empresas usualmente criam uma área de $\mathrm{P} \& \mathrm{D}$ a qual é responsável pelo processo de geração de oportunidades, seleção e implementação. O objetivo deste trabalho é construir um modelo de avaliação que auxilie o decisor a compreender as potencialidades e oportunidades de aperfeiçoamento para enfrentar os desafios do negócio no processo de avaliação e seleção de projetos de $\mathrm{P} \& \mathrm{D}$. Tendo em vista as necessidades de expansão do entendimento do contexto pelo decisor, optou-se pela metodologia MCDA-C como ferramenta para ajudá-lo nesta atividade. O uso da metodologia MCDA-C permitirá ao decisor identificar, organizar, mensurar, integrar e gerenciar os aspectos críticos para o sucesso da empresa segundo sua percepção. A expansão deste conhecimento permitirá ao decisor de uma forma transparente e cientificamente fundamentada construir, avaliar e selecionar alternativas de P\&D que melhor atendam aos interesses da organização.

A continuidade do trabalho deu-se por meio de uma entrevista semi-estruturada feita com o decisor. Dessa entrevista, vista como um brainstorming foram identificados 97 Elementos Primários de Avaliação (EPA's) e a partir deles, construídos 136 conceitos com seus pólos-opostos. A partir de tais conceitos, por meio de agrupamentos, foi possível construir a Árvore de Valor, apresentada na figura a seguir:

Figura 3 - Árvore de Valor

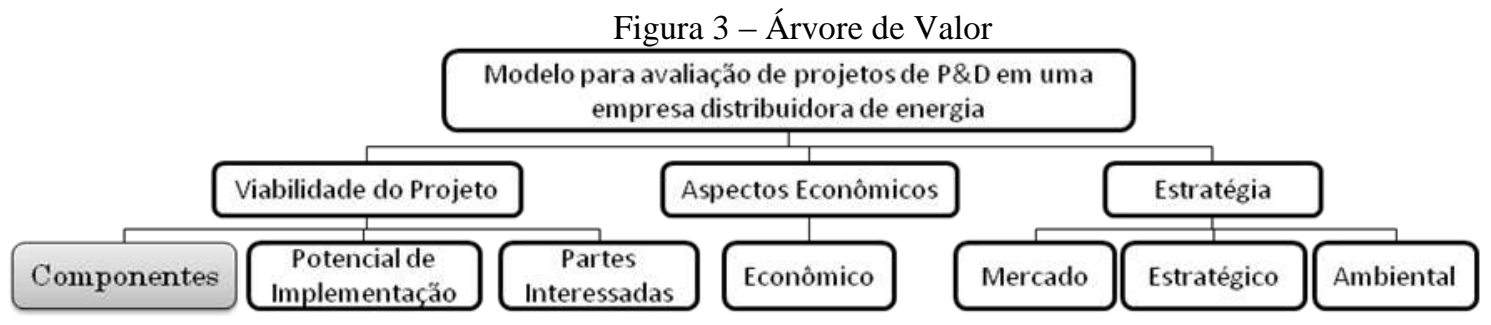

Fonte: Pesquisa de campo (2008)

Organizados os conceitos de forma hierárquica, divididos entre conceitos-meios e conceitosfins, foi possível definir os clusters. O resultado para a área "Componentes" pode ser visualizado na figura a seguir. 
Figura 4 - Mapa de Causa e Efeito para construção dos clusters para a área "Componentes"

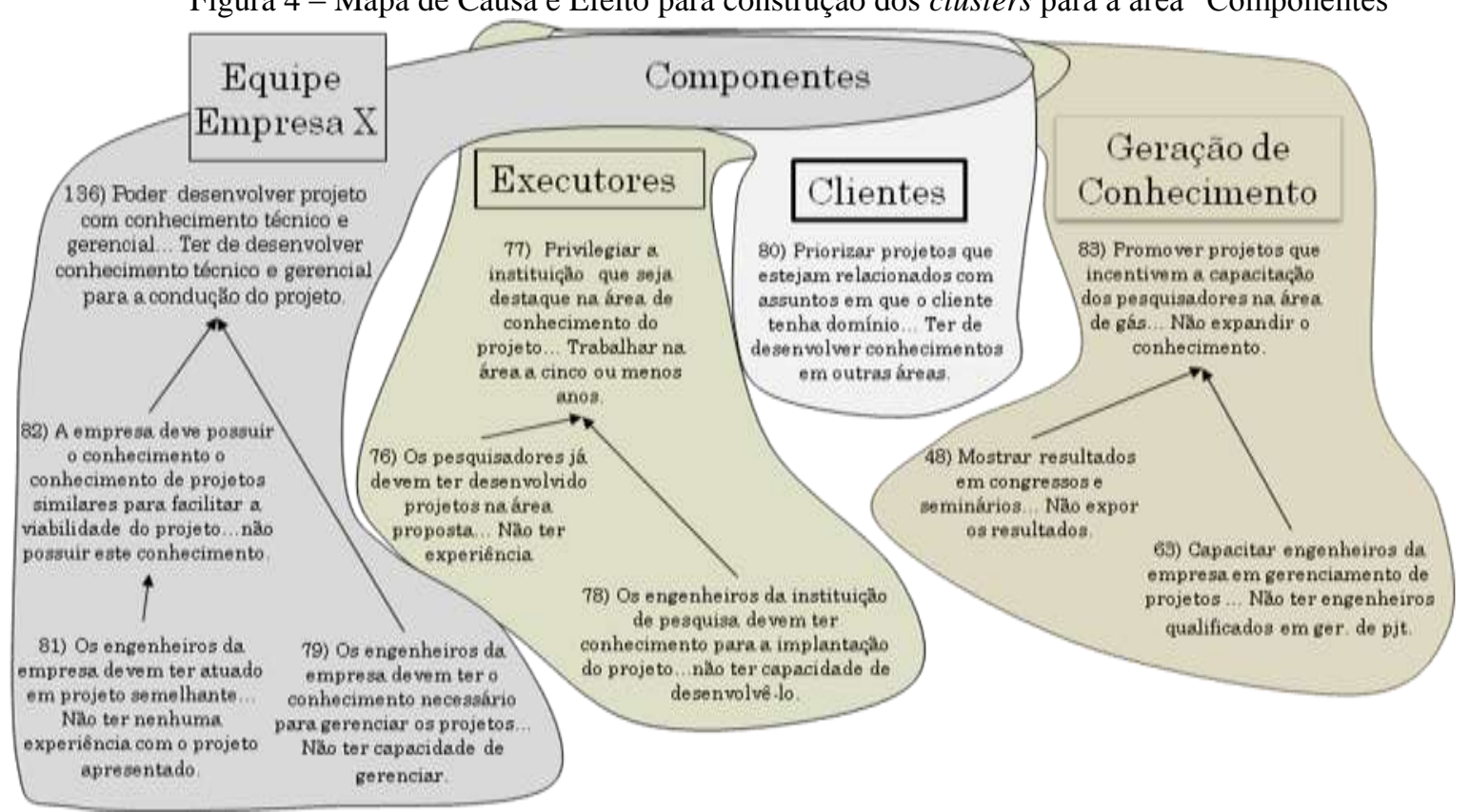

Fonte: Pesquisa de campo (2008)

Da criação dos clusters, foram definidos os Pontos de Vista Elementares, exemplificado pela figura 5.

Figura 5 - Ponto de Vistas Elementares para a área "Componentes"

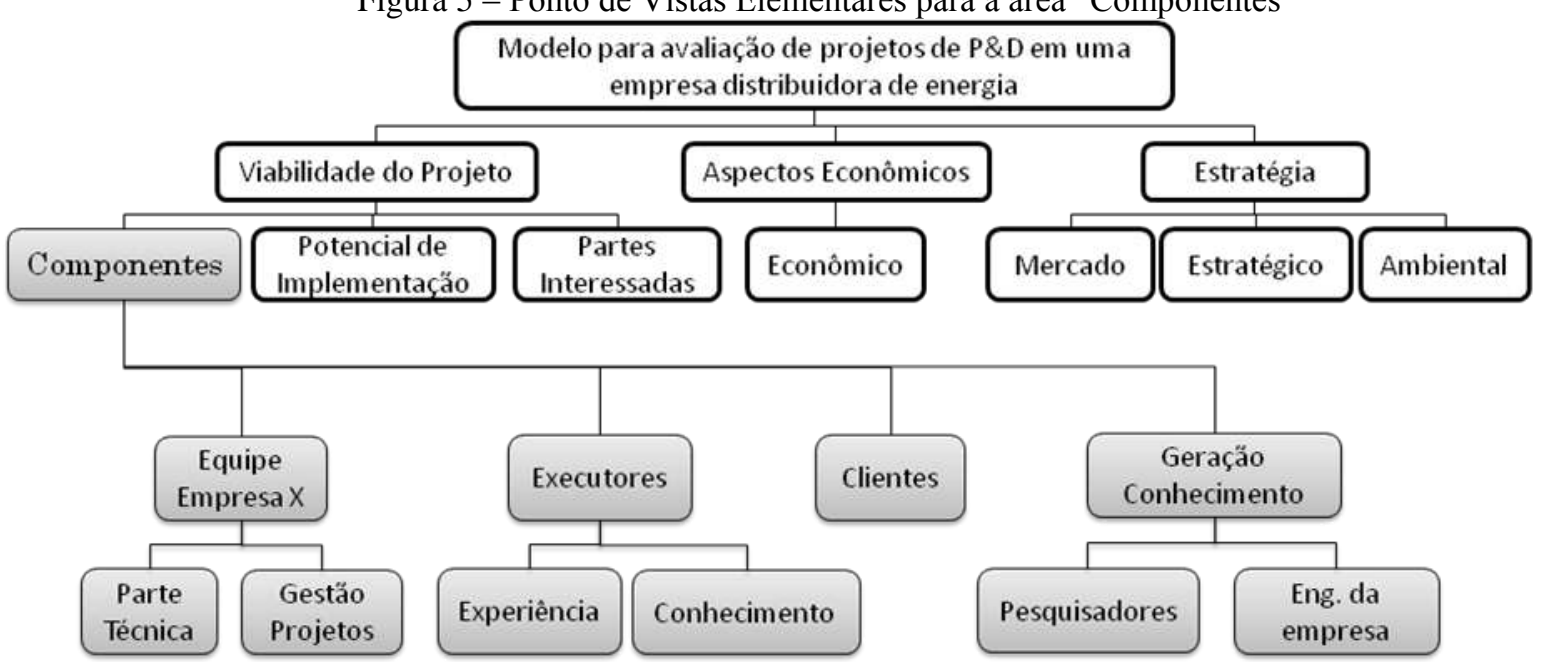

Fonte: Pesquisa de campo (2008)

Para terminar a fase de Estruturação, torna-se necessário construir uma escala ordinal que permita mensurar o desempenho de cada alternativa avaliada em cada ponto de vista. Essa escala, denominada descritor, possui níveis de impacto sendo que destes dois são níveis de referência, também chamados de âncoras. A figura 6 apresenta os níveis de impacto do descritor vinculado ao Ponto de Vista Elementar "Parte Técnica". Tal como o descritor exemplificado na figura a seguir, foram construídos os demais descritores para cada um dos 53 critérios identificados e definidos seus níveis de referência, de tal forma que, posteriormente, fosse possível mensurar e avaliar o desempenho de cada uma das alternativas no modelo construído. 

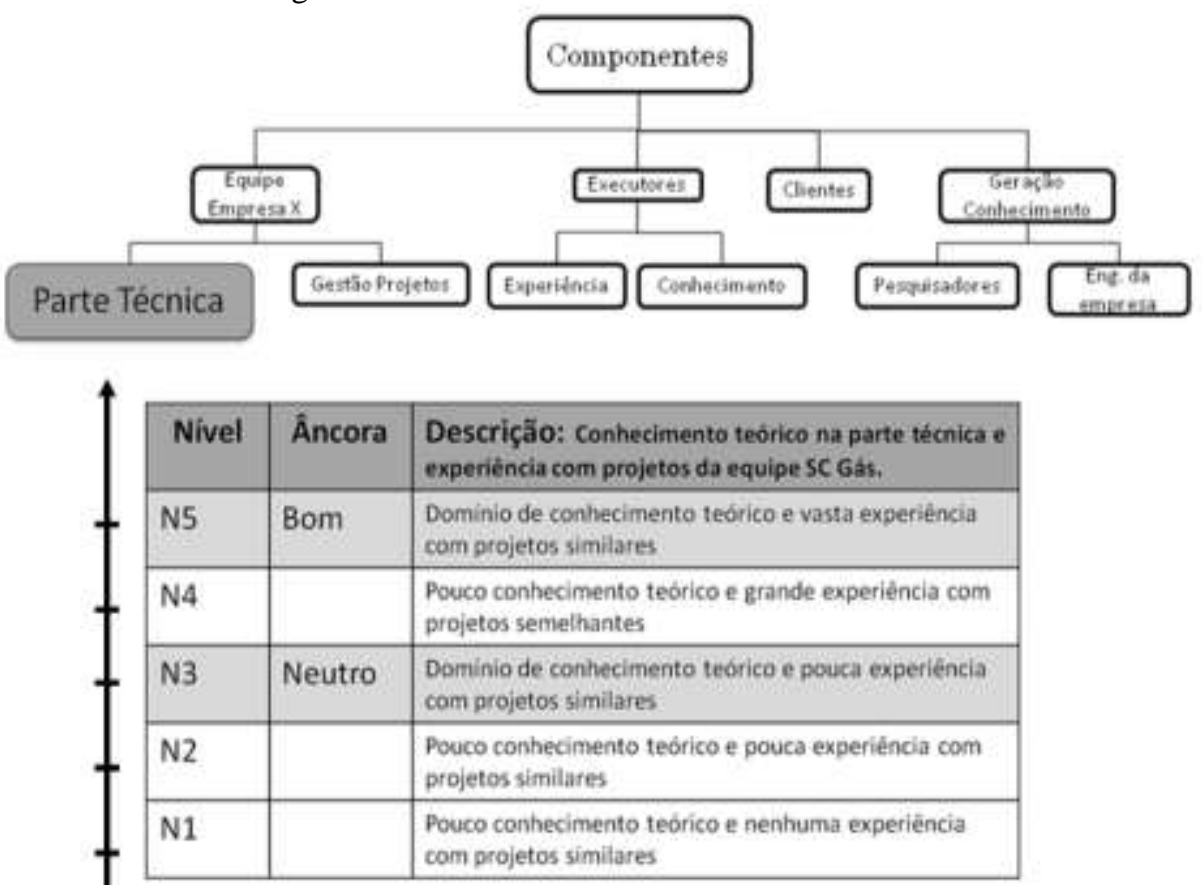

Fonte: Pesquisa de campo (2008)

Assim, constata-se que, a partir da Fase de Estruturação, é possível construir o conhecimento sobre o presente problema, identificando e organizando os aspectos julgados importantes em um determinado contexto.

Argumenta-se, então, que a MCDA-C consegue satisfazer a necessidade identificada anteriormente de ter procedimento para identificação de critérios ad hoc. Assim, a avaliação e seleção dos projetos de $\mathrm{P} \& \mathrm{D}$ poderão ser realizadas considerando-se os aspectos julgados importantes pelo decisor do contexto.

\section{b) Fase de avaliação}

Com todos os descritores construídos, o próximo passo é criar as funções de valor, visando determinar o grau de atratividade entre os diferentes níveis de desempenho dos descritores, e determinar as taxas de substituição para o modelo.

Como primeira etapa, ordena-se os descritores, segundo a preferência do decisor, utilizando a Matriz de Roberts, de acordo com a tabela 7, apresentada abaixo. Essa ordenação tem o objetivo de tornar possível a construção das funções de valor.

Tabela 7 - Matriz de Roberts - 1.1.1.1.1 Parte Técnica

\begin{tabular}{|c|c|c|c|c|c|c|c|}
\hline $\begin{array}{c}\text { Equipe Empresa X } \\
\text { - Parte Técnica }\end{array}$ & $\mathrm{N} 5$ & $\mathrm{~N} 4$ & $\mathrm{~N} 3$ & $\mathrm{~N} 2$ & $\mathrm{~N} 1$ & Soma & Ordem \\
\hline $\mathrm{N} 5$ & $\mathrm{xxxx}$ & 1 & 1 & 1 & 1 & 4 & $1^{\mathrm{o}}$ \\
\hline $\mathrm{N} 4$ & 0 & $\mathrm{xxxxx}$ & 1 & 1 & 1 & 3 & $2^{\mathrm{o}}$ \\
\hline $\mathrm{N} 3$ & 0 & 0 & $\operatorname{xxxxx}$ & 1 & 1 & 2 & $3^{\mathrm{o}}$ \\
\hline
\end{tabular}




\begin{tabular}{|c|c|c|c|c|c|c|c|}
$\mathrm{N} 2$ & 0 & 0 & 0 & $\operatorname{xxxxx}$ & 1 & 1 & $4^{\circ}$ \\
\hline $\mathrm{N} 1$ & 0 & 0 & 0 & 0 & $\operatorname{xxxxx}$ & 0 & $5^{\mathrm{o}}$ \\
\hline
\end{tabular}

Fonte: Pesquisa de campo (2008)

Para a construção das funções de valor utiliza-se do julgamento semântico com o software MACBETH. Assim, por meio de entrevista estruturada com o decisor, utilizando matrizes formadas com níveis de desempenho dos descritores de cada Ponto de Vista Elementar, o decisor pode julgar a diferença de atratividade entre as alternativas, julgando-as aos pares. A seguir, na tabela 8, apresenta-se a matriz do PVE1 "Parte Técnica" juntamente com o julgamento do decisor quanto à diferença entre cada nível de impacto.

Tabela 8 - Matriz formada por descritores para entrevista com decisor - 1.1.1.1.1 Parte Técnica

\begin{tabular}{|c|c|c|c|c|c|}
\hline $\begin{array}{c}\text { Equipe Empresa X } \\
\text { - Parte Técnica }\end{array}$ & N5 & N4 & N3 & N2 & N1 \\
\hline N5 & xxxx & Moderada & Moderada & Forte & Extrema \\
\hline N4 & & xxxxx & Muito Fraca & Fraca & Muito Forte \\
\hline N3 & & & xxxxx & Fraca & Forte \\
\hline N2 & & & & xxxxx & Moderada \\
\hline N1 & & & & & xxxxx \\
\hline
\end{tabular}

Fonte: Pesquisa de campo (2008)

Após o julgamento semântico do decisor, observa-se na Tabela 9 que a segunda coluna refere-se aos níveis de ancoragem do descritor e a quarta e última coluna representa a escala cardinal construída.

Tabela 9 - Descritor e função de valor do critério 6.3.2.1.1.1.1.1 Parte Técnica

\begin{tabular}{c|c|c|c}
\hline \hline \multirow{2}{*}{ Nível de Impacto } & Nível de Referência & Descrição & $\begin{array}{c}\text { Função de Valor } \\
\text { (Macbeth) }\end{array}$ \\
\hline \hline $\mathrm{N} 1$ & Bom & $\begin{array}{c}\text { Domínio de conhecimento teórico e vasta } \\
\text { experiência com projetos similares }\end{array}$ & 100 \\
\hline $\mathrm{N} 2$ & Neutro & $\begin{array}{c}\text { Pouco conhecimento teórico e grande experiência } \\
\text { com projetos semelhantes }\end{array}$ & 40 \\
\hline $\mathrm{N} 3$ & & $\begin{array}{c}\text { Domínio de conhecimento teórico e pouca } \\
\text { experiência com projetos similares }\end{array}$ & 0 \\
\hline
\end{tabular}




\begin{tabular}{l|l|c|c}
\hline N4 & & $\begin{array}{c}\text { Pouco conhecimento teórico e pouca experiência } \\
\text { com projetos similares }\end{array}$ & -60 \\
\hline N5 & & $\begin{array}{c}\text { Pouco conhecimento teórico e nenhuma } \\
\text { experiência com projetos similares }\end{array}$ & -120 \\
\hline
\end{tabular}

Fonte: Pesquisa de campo (2008)

No gráfico 3, a escala é disposta graficamente para melhor visualização da função de valor que esta representa. Esta escala representa o quanto vale, em termos quantitativos, passar de um nível de desempenho para o outro.

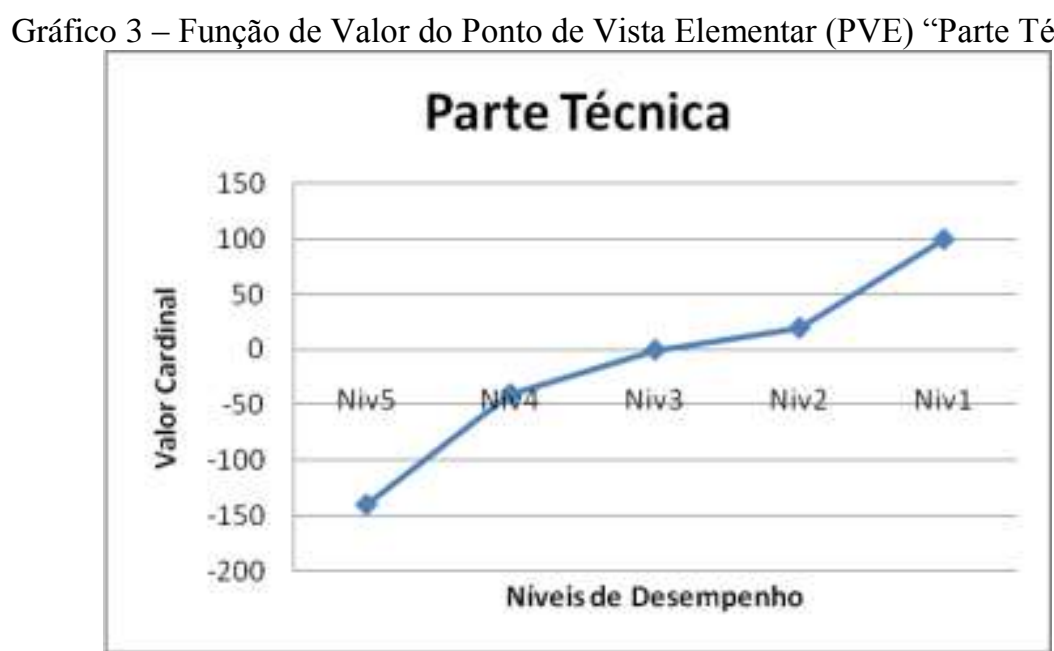

Fonte: Pesquisa de campo (2008)

Percebe-se que nas ferramentas analisadas no referencial teórico, a mensuração é realizada negligenciando a transferência das escalas ordinais para cardinais. No único artigo que realiza tal etapa, Bitman e Sharif (2008), ignoram a necessidade de se ter a ancoragem pelos níveis de referência para se construir a escala cardinal. Nesse sentido, a MCDA-C atende a necessidade de avaliar cada critério do modelo em termos numéricos de maneira consistente.

Para a construção das Taxas de Substituição utiliza-se do método Comparação Par-a-Par, ou seja, apenas dois critérios são julgados por vez. Assim, são criadas três alternativas com as diferentes opções de desempenho. Ensslin, Dutra e Ensslin (2000). Como ilustração os critérios utilizados foram o PVE1 "Parte Técnica" e PVE2 "Gestão de Projetos", conforme exemplificado pela figura 7. 
Figura 7 - Alternativas A1, A2 e A0 para PVE1 e PVE2

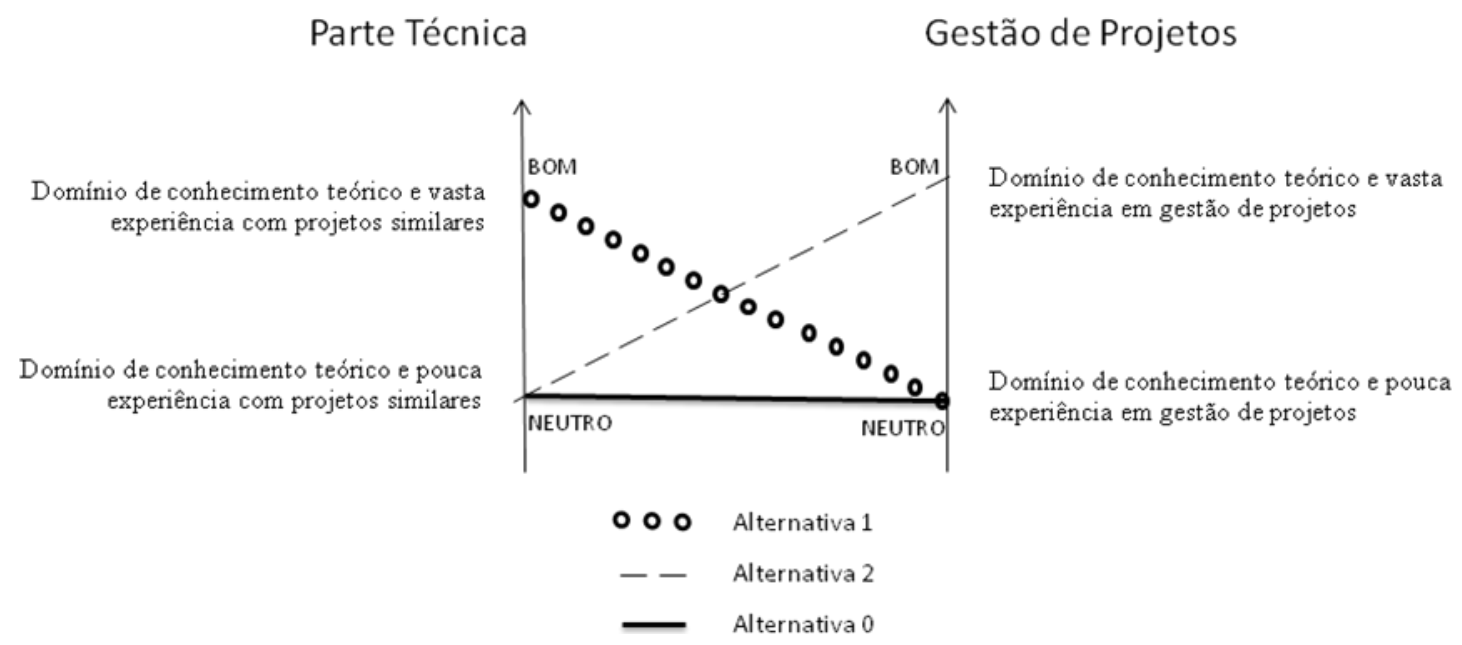

Fonte: Pesquisa de campo (2008)

Após a criação das alternativas estas são ordenadas de acordo com a preferência. No exemplo da tabela 10, a primeira alternativa é a preferível, ou seja, nível BOM no PVE1 e nível NEUTRO no PVE2.

Tabela 10 - Julgamento das alternativas

\begin{tabular}{|c|c|c|c|c|c|}
\hline $\begin{array}{c}\text { Parte Técnica X } \\
\text { Gestão de Projetos }\end{array}$ & A1 & A2 & A0 & Soma & Ordem \\
\hline A1 & xxxx & 1 & 1 & 2 & $1^{\circ}$ \\
\hline A2 & 0 & $\operatorname{xxxxx}$ & 1 & 1 & $2^{\circ}$ \\
\hline A0 & 0 & 0 & $\operatorname{xxxxx}$ & 0 & $3^{\circ}$ \\
\hline
\end{tabular}

Fonte: Pesquisa de campo (2008)

Posteriormente, faz-se um novo julgamento semântico para saber a diferença de atratividade entre um critério e outro. Desta forma são obtidas as taxas de substituição para os Pontos de Vistas Elementares 1 e 2, como o apresentado na Tabela 11 .

Tabela 11 - Obtenção das taxas de substituição do PVE "Parte Técnica"

\begin{tabular}{|c|c|c|c|c|c|}
\hline $\begin{array}{c}\text { Parte Técnica X } \\
\text { Gestão de Projetos }\end{array}$ & A1 & A2 & A0 & $\begin{array}{c}\text { Escala } \\
\text { Atual }\end{array}$ & $\%$ \\
\hline A1 & xxxx & Moderada & $\begin{array}{c}\text { Muito } \\
\text { Forte }\end{array}$ & 100 & $64 \%$ \\
\hline A2 & 0 & xxxxx & Forte & 57 & $36 \%$ \\
\hline A0 & 0 & 0 & xxxxx & 0 & $0 \%$ \\
\hline \multicolumn{7}{|c|}{ SOMA }
\end{tabular}

Fonte: Pesquisa de campo (2008)

Essas taxas orientam o decisor a tomar decisões, pois possibilitam a comparação entre todas as alternativas disponíveis de ação. 
A seguir, apresenta-se a Figura 8 como representação do resultado entre o confronto das alternativas A1, A2 e A0 feito anteriormente, para os PVE 1 e 2.

Figura 8 - Taxas de Substituição dos PVE 1 e 2 - Parte Técnica e Gestão de Projetos

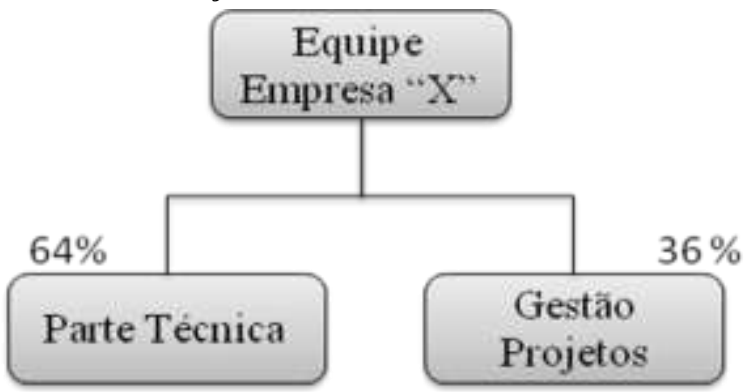

Fonte: Pesquisa de campo (2008)

Como parte final da fase de avaliação as taxas de substituição de todos os pontos de vistas fundamentais são obtidas. A partir dessas taxas é possível traçar o perfil de impacto de cada alternativa, a fim de avaliar e selecionar o projeto mais adequado à empresa no momento.

A integração na MCDA-C é realizada a partir da definição de níveis de referência e comparação par-a-par dos critérios. Assim, consegue-se obter de maneira direta as taxas de substituição. Dessa maneira, a metodologia utilizada consegue integrar os critérios de maneira fundamentada cientificamente.

A Figura 9 mostra o porcentual de cada PVF, ou seja, a contribuição que cada PVF tem para o total do modelo: Componentes - 18.5\%; Potencial de Implementação - 14.6\%; Partes Interessadas - 9.9\%; Econômico - 23\%; Mercado - 7.8\%; Estratégico - 11.2\%; Ambiental $14.9 \%$.

Figura 9 - Taxas de Substituição dos PVFs

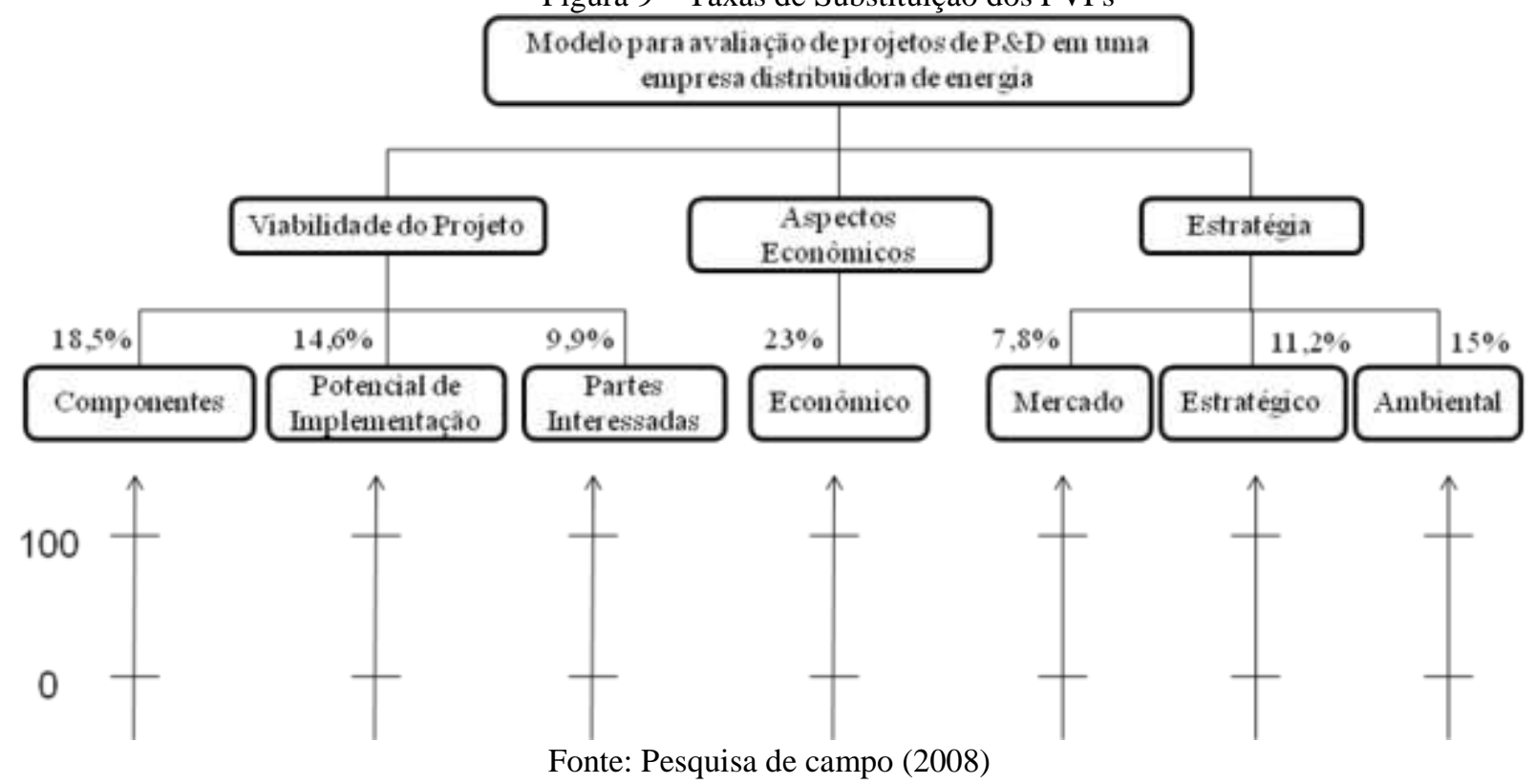

A título de ilustração, dois projetos hipotéticos foram julgados e suas pontuações globais 
calculadas. O projeto 1 atingiu uma pontuação igual a 59, enquanto o projeto 2 apresentou 60,4 pontos. O perfil de impacto de cada projeto, bem como a apresentação de todas as taxas de compensação, está representado pela figura 10.

Figura 10 - Taxas de Substituição dos PVFs e Perfil de Impacto dos Projetos 1 e 2

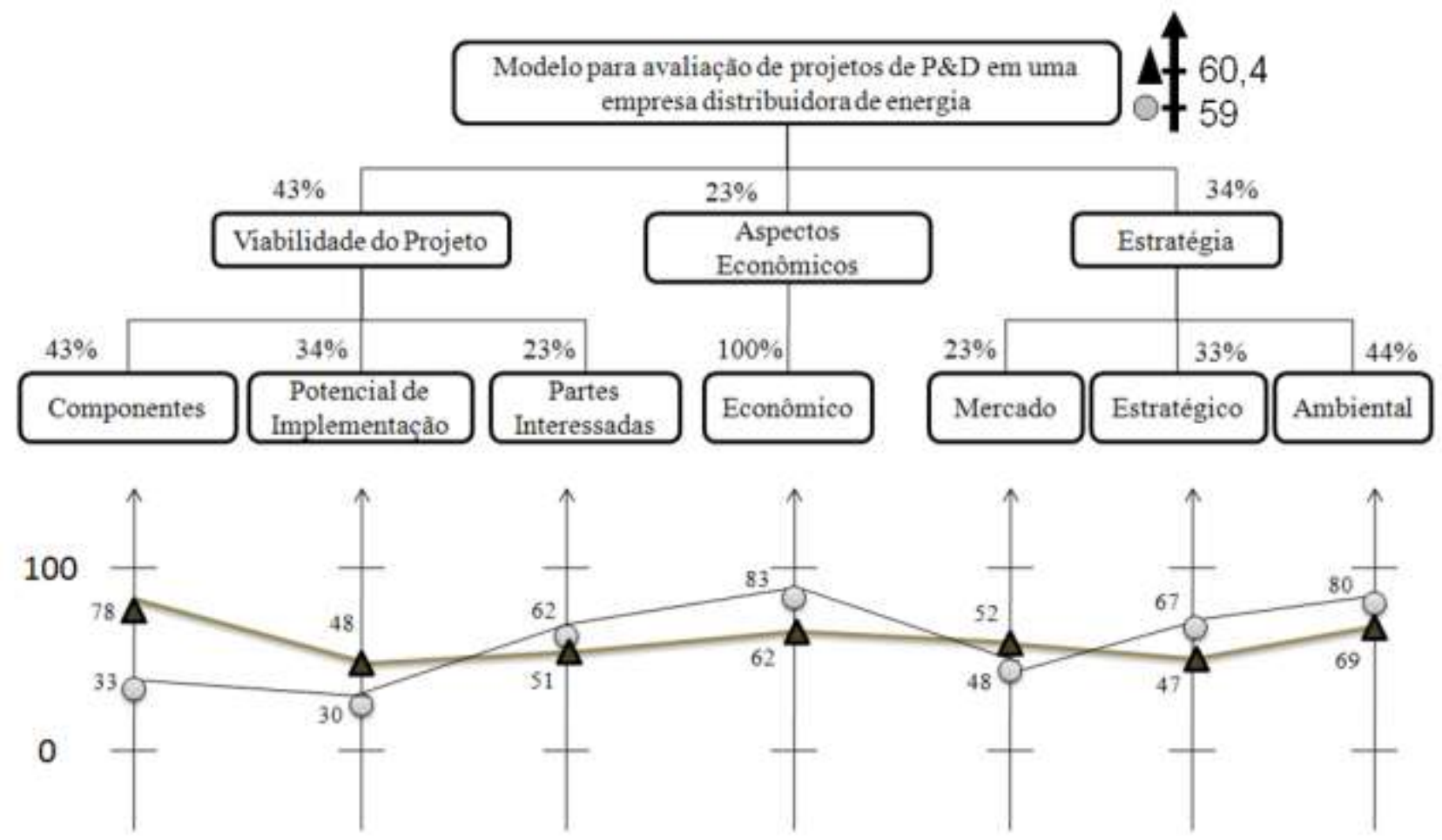

Projeto $1: 0,43\{0,43(33)+0,34(30)+0,23(62)\}+0,23\{1(83)\}+0,34\{0,23(48)+0,33(67)+0,44(80)\}=59$

$\Delta$ Projeto $2: 0,43\{0,43(78)+0,34(48)+0,23(51)\}+0,23\{1(62\}+0,34\{0,23(52)+0,33(47)+0,44(69)\}=60,4$

Fonte: Pesquisa de campo (2008)

Pode-se notar que, apesar de o projeto 2 apresentar uma pontuação muito melhor no que se diz respeito à Viabilidade do Projeto, este apresenta praticamente a mesma pontuação que o projeto 1. Isso acontece porque o primeiro projeto foi responsável por 83 pontos no PVF "Econômico", enquanto o projeto 2 obteve uma pontuação no valor de 62. Essa diferença de 21 pontos foi representativa já que o PVF "Econômico" responde sozinho por $23 \%$ do total da pontuação do modelo.

\section{c) Fase de Recomendação}

Como visto anteriormente, na figura 9, o PVF "Econômico" é responsável por 23\% da pontuação global, o que mostra que este PVF é um dos aspectos críticos da empresa, seguido pelo PVF “Componentes", responsável por 18,5\% da pontuação global e "Ambiental” com 14.9\%, "Potencial de implementação" abrangendo 14.6\% da pontuação global, "Estratégico" com 11.2\%, "Partes interessadas" com 9.9\% e, finalmente, "Mercado" com 7.8\% da pontuação global.

A partir deste diagnóstico é possível saber que se um determinado projeto apresentar uma 
boa pontuação nos PVF's "Componentes" e "Econômico", mesmo que não possua uma boa performance em outros PVF's menos relevantes, tais como "Partes Interessadas" e "Mercado", este provavelmente terá ótima vantagem competitiva. Desta forma, torna-se possível o gerenciamento da seleção de projetos de $\mathrm{P} \& \mathrm{D}$.

\section{Considerações Finais}

Ao iniciar o processo de seleção dos projetos de $\mathrm{P} \& \mathrm{D}$ identificou-se que se tratava de um problema multicritério devido aos aspectos diferenciados a serem avaliados no contexto. Também se pode identificar que não estavam claros quais eram os critérios que deveriam ser considerados e a mensuração do desempenho de cada critério era abstrata. Assim, a seleção dos projetos de P\&D que seria realizada tornou-se um processo complexo, pois não se sabia o que se desejava (objetivos), além de não se dispor de um instrumento que permitisse identificar alternativas.

Deste modo, o presente artigo debateu sobre metodologias empregadas para avaliar e selecionar projeto de $P \& D$ e apresentou uma nova metodologia que foi capaz de identificar, mensurar, integrar e conseqüentemente gerenciar os aspectos considerados na seleção de projetos de P\&D em uma empresa distribuidora de energia. Desta forma, foi apresentada a metodologia Multicritério de Apoio à Decisão - Construtivista (MCDA-C) que atendeu as três etapas do gerenciamento de seleção de projetos de $\mathrm{P} \& \mathrm{D}$.

A partir do objetivo principal, foram formulados cinco objetivos específicos, sendo eles: (i) identificar, (ii) organizar, (iii) mensurar, (iv) integrar e (v) gerenciar os aspectos críticos para o sucesso da empresa segundo sua percepção.

No que diz respeito ao primeiro objetivo específico, foram identificados sete Pontos de Vistas Fundamentais, divididos em três grandes áreas sendo elas: Viabilidade do Projeto, Aspectos Econômicos e Estratégia. Esses pontos de vistas foram apresentados na Figura 3 como uma estrutura arborescente.

Quanto ao segundo objetivo específico, o modelo foi organizado em 53 (cinqüenta e três) critérios dos quais sete - Parte Técnica, Gestão de Projetos, Experiência, Conhecimento, Clientes, Pesquisadores e Engenharia da Empresa - referentes ao Ponto de Vista Fundamental "Componentes", foram apresentados na Figura 5.

Após a construção de todos os pontos de vistas, foram criadas escalas ordinais, aqui representadas por descritores para cada critério, onde foi possível mensurar o desempenho das ações localmente. A partir daí foram construídas escalas cardinais, aqui representadas por funções de valor que identificaram as diferenças de atratividade entre cada nível do descritor. Para explicitar os descritores e as funções de valor foi utilizada a tabela 9 que explorou a PVE1 "Parte Técnica". O terceiro objetivo específico, portanto, foi cumprido. 
A integração, quarto objetivo específico, foi realizada a partir da criação das taxas de substituição que permitiram a avaliação global dos possíveis projetos. Uma representação das taxas de substituição para os PVF's foi apresentada na figura 9, bem como uma ilustração de dois possíveis projetos. Duas situações hipotéticas foram realizadas. Na primeira situação o projeto obteve um total de 59 pontos, já o segundo projeto, 60.4 pontos. Observou-se que, apesar de variações de pontuação em todos os critérios, a diferença global entre as situações hipotéticas foi irrelevante, 1.4 ponto. Isso ocorreu devido ao fato de os PVF’s "Econômico" e "Componentes", representarem $18.5 \%$ e $23 \%$, respectivamente, o que soma $41.5 \%$ da pontuação global. Essa porcentagem os torna dignos de uma atenção maior no que se refere à avaliação e seleção de projetos de $\mathrm{P} \& \mathrm{D}$.

O gerenciamento, quinto e último objetivo específico, se deu a partir de análises feitas quanto à influência de cada critério sobre a pontuação global. Por meio do gerenciamento foi possível observar quais eram os critérios mais significativos, aqueles que respondiam por maior parte da pontuação global e assim auxiliar na tomada de decisão.

Constata-se, ainda, que o modelo multicritério apresentado no presente artigo atende às preocupações identificadas nos estudos internacionais sobre P\&D, visto que todos os oito artigos analisados no referencial teórico apresentavam modelos multicritério. Entretanto, os artigos analisados não identificaram, mensuraram e/ou integraram os objetivos simultaneamente, não oferecendo subsídios para a realização do gerenciamento.

Como limitações do presente artigo, apontam-se os aspectos: (i) o modelo foi desenvolvido para uma empresa específica, porém não foi implantado; (ii) os oito artigos referenciados no trabalho foram obtidos a partir do referencial adotado, contudo poderia ser feito com outras bases de dados; e (iii) o modelo foi construído exclusivamente para a empresa "x" e não pode ser replicado visto que as preocupações e percepções variam de acordo com o decisor, o modelo é personalizado. No entanto, pode-se replicar o processo de criação do mesmo para outras empresas.

Como recomendações para futuras pesquisas sugerem-se a implantação do modelo na empresa e replicação do processo da metodologia MCDA-C para o desenvolvimento de modelos para outras empresas. Uma segunda recomendação, seria a investigação do Referencial Teórico no contexto brasileiro.

\footnotetext{
Abstract

The world observes an increase of investments in research to develop new products or new technologies. In order to achieve these necessities, companies usually deposited in the Research \& Development $(R \& D)$ the responsibility for the process of creation, selection and implementation of projects. The goal of this study, descriptive and exploratory, is to present a process to build a model that supports the construction of stakeholders' knowledge in a particular company in order to identify opportunities to build and / or optimize R\&D projects. The process proposed is illustrated
} 
for an organization focused on innovation. The strategic objectives for R\&D area were built and the performance indicators which explain them were made clear. This knowledge has highlighted that the strategic objectives; "Economic" and "Components" are responsible for almost 50\% of what the company is looking for with the R\&D projects. The methodology used provides for the managers a reasoned knowledge in a model that captures the view of them to clarifying the issues they deemed as necessary and sufficient to represent what they seek in R\&D. The process used constructed scales to measure aspects regarded as necessary and sufficient to assess the new products development degree or new technologies and integrated them allowing to be used to generate improvement in the projects and measure their contributions.

Keywords: research and development; evaluation; multicriteria decision aid - constructivist (MCDA-C).

\section{Referências}

AZEVEDO, J. Aplicação da Metodologia Multicritério de Apoio à Decisão na Seleção de Centros de Usinagem para uma Central de Usinagem. Dissertação de Mestrado em Engenharia de Produção. Florianópolis. PPGEP/UFSC. 2001.

BANA E COSTA, C. A. et al. Decision Support Systems in Action: Integrated Application in a Multicriteria Decision Aid Process. European Journal of Operational Research, v. 113, n.2, p.315-335, 1999.

\section{cross ref}

BANA E COSTA, C. A.; VANSNICK, J. C. Uma nova abordagem ao problema da construção de uma função de valor cardinal: MACBETH. Investigação Operacional, 15, 15-35. 1995.

BITMAN, W.; SHARIF, N. A conceptual framework for ranking R\&D projects. IEEE Transactions on Engineering Management. Vol. 55, n. 2, p. 267-278, 2008.

\section{cross ref}

BORTOLUZZI, S. C.; ENSSLIN, S. R.; ENSSLIN, L. Avaliação de desempenho multicritério como apoio à gestão de empresas: aplicação em uma empresa de serviços. Gestão \& Produção, v.18, n.3, p.633-650. 2011.

\section{cross ref}

COLDRICK, S. et al. In: A decision framework for R \& D project selection. IEEE International Engineering Management Conference. p. 413-418, 2002.

DEY, P. K. Integrated project evaluation and selection using multiple-attribute decision-making technique. International Journal of Production Economics. Vol. 103, n. 1, p. 90-103, 2006.

cross ref

EDEN, C. JONES, S., SIMS, D. Messing about in problems. Oxford: Pergamon, 1983.

ENSSLIN, S. R. A incorporação da perspectiva sistêmico-sinergética na metodologia MCDA-construtivista: uma ilustração de implementação. 2002. 461 p. (Doutorado). Programa de Pós-Graduação em Engenharia de Produção PPGEP, Universidade Federal de Santa Catarina - UFSC, Florianópolis, 2002.

ENSSLIN, L.; DUTRA, A.; ENSSLIN, S. R.. MCDA: A constructivist approach to the management of human resources at a governmental agency. Intl. Trans. In Op. Res. 7 (2000) 79-100.

ENSSLIN, L.; GIFFHORN, E.; ENSSLIN, S. R.; PETRI, S. M.; VIANNA, W. B. Avaliação do desempenho de empresas terceirizadas com o uso da metodologia multicritério de apoio à decisão- construtivista. Revista Pesquisa Operacional, V.30, No. 1, p. 125 - 152, Janeiro a Abril de 2010. Versão impressa ISSN 0101-7438 / versão online ISSN 1678-5142.

ENSSlin, L.; MONTIBEller, G. N.; NORONHA, S. M. Apoio à Decisão: Metodologias para Estruturação de Problemas e Avaliação Multicritério de Alternativas. Florianópolis: Ed. Insular, p. 187 e 241, 2001. 
GIL, A. C. Métodos e técnicas de pesquisa social. 5 ed. São Paulo, Atlas,. 2010.

KEENEY, R. L. Value focused-thinking: a path to creative decision-making. Cambridge: Harvard Univ. Press, 1992.

KELVIN, W. T. Popular lectures and addresses. 1891-1894.

LACERDA, R. T. O.; ENSSLIN, L.; ENSSLIN, S. R. A performance measurement view of IT project management. International Journal of Productivity and Performance Management, v.60, n.2, p.132-151. 2011.

\section{cross ref}

LEE, J. W.; KIM, S. H. Using analytic network process and goal programming for interdependent information system project selection. Computers \& Operations Research. Vol 27, n. 4, p. 367-382, 2000.

\section{cross ref}

MEADE, L. M.; PRESLEY, A. R and D project selection using the analytic network process. IEEE Transactions on Engineering Management. Vol. 49, n. 1, p. 59-66, 2002.

\section{cross ref}

PILLAI, A. S.; JOSHI, A.; RAO, K. S. Performance measurement of R and D projects in a multi-project, concurrent engineering environment. International Journal of Project Management. Vol. 20, n. 2, p. 165-177, 2002.

\section{cross ref}

QUIRINO, M. G. Incorporação das relações de subordinação na matriz de ordenação-Roberts em MCDA quando os axiomas de assimetria e transitividade negativa são violados. Tese de Doutorado em Engenharia de Produção. Florianópolis. PPGEP/UFSC. 2002.

RICHARDSON, R. J. Pesquisa Social: métodos e técnicas São Paulo: Atlas. 2008.

SHIN, C.-O.; YOO, S.-H.; KWAK, S.-J. Applying the analytic hierarchy process to evaluation of the national nuclear R\&D projects: the case of Korea. Progress in Nuclear Energy. Vol. 49, n. 5, p. 375-384, 2007.

\section{cross ref}

STUMMER, C.; HEIDENBERGER, K. Interactive R\&D portfolio analysis with project interdependencies and time profiles of multiple objectives. IEEE Transactions on Engineering Management. Vol. 50, n. 2, p. 175-183, 2003.

\section{cross ref}

YIN, R. K. Estudo de caso: planejamento e métodos. 3. ed. Porto Alegre: Bookman. 2005.

\section{Dados dos autores:}

\section{Nome completo: Leonardo Ensslin}

Filiação institucional: UFSC - Universidade Federal de Santa Catarina

Departamento: Departamento de Engenharia de Produção e Sistemas

Função ou cargo ocupado: Professor Titular, Coordenador do LabMCDA.

Endereço completo para correspondência: Rua Frei Caneca, 629, Apto 402- Florianópolis, SC -

Brasil; CEP 88.025 - 000

Telefones para contato: (48) 3721-7022

e-mail: ensslin@deps.ufsc.br 
Nome completo: Maurício Andreis

Filiação institucional: UFSC - Universidade Federal de Santa Catarina

Departamento: Departamento de Engenharia de Produção e Sistemas

Função ou cargo ocupado: Aluno e pesquisador.

Endereço completo para correspondência (bairro, cidade, estado, país e CEP): Bairro Trindade, Florianópolis, Santa Catarina, Brasil, CEP 88036-400, Rua Luis Oscar de Carvalho, $\mathrm{n}^{\circ}$ 75, Bloco A8, Apartamento 31.

Telefones para contato: (48) 9946-1164

e-mail: mauricioandreis@gmail.com

Nome completo: Thalita Assad Medaglia

Filiação institucional: UFSC - Universidade Federal de Santa Catarina

Departamento: Departamento de Engenharia de Produção e Sistemas

Função ou cargo ocupado: Engenheira de Produção Mecânica

Endereço completo para correspondência (bairro, cidade, estado, país e CEP): Itacorubi, Florianópolis, Santa Catarina, Brasil, CEP 88034-001, Rod. Admar Gonzaga, 841 apt 618. Telefones para contato: (48) 8842-0162

e-mail: thalitamedaglia@ hotmail.com

\section{Nome completo: Haline De Carli}

Filiação institucional: UFSC - Universidade Federal de Santa Catarina

Departamento: Departamento de Engenharia de Produção e Sistemas

Função ou cargo ocupado: Engenheira de Produção Mecânica

Endereço completo para correspondência (bairro, cidade, estado, país e CEP): Bairro Trindade, Florianópolis, Santa Catarina, Brasil, CEP 88036-001, Rua Lauro Linhares, no 970, Bloco A, Apartamento 104.

Telefones para contato: (48) 99405-1679

e-mail: halinedecarli@gmail.com

\section{Nome completo: Sandra Rolim Ensslin}

Filiação institucional: UFSC - Universidade Federal de Santa Catarina

Departamento: Departamento de Ciências Contábeis

Função ou cargo ocupado: Professora Adjunto 2

Endereço completo para correspondência: Rua Frei Caneca, 629, Apto 402- Florianópolis, SC Brasil; CEP 88.025 - 000; 
Telefones para contato: (48) 3209 - 1916

e-mai: sensslin@gmail.com

Enviado em: 07/11/2011

Aprovado em: 03/04/2012 